\title{
Aproximación a la tecnología cerámica y metalúrgica en las quebradas altas del Noroeste Argentino: el caso de Tacuil, valle Calchaquí medio, Salta, Argentina
}

\section{Approximation to the ceramic and metallurgical technology in high ravines of the Argentine Northwest: the case of Tacuil, Valley Calchaquí medio, Salta, Argentina}

\author{
María Cecilia Castellanos ${ }^{1}$ https://orcid.org/0000-0003-3904-3190 \\ María Florencia Becerra $^{2}$ https://orcid.org/0000-0001-6302-7452 \\ Verónica Isabel Williams ${ }^{3}$ https://orcid.org/0000-0003-4194-5214 \\ ${ }^{1}$ Instituto de las Culturas (IDECU) - Universidad de Buenos Aires - CONICET, Buenos Aires, \\ ARGENTINA. Email: cecicastellan88@yahoo.com.ar \\ ${ }^{2}$ CONICET - Universidad de Buenos Aires, Facultad de Filosofía y Letras, Instituto de \\ Arqueología, Buenos Aires, ARGENTINA. Email: florenciabecerra@gmail.com \\ ${ }^{3}$ Instituto de las Culturas (IDECU) - Universidad de Buenos Aires - CONICET, \\ Buenos Aires, ARGENTINA. Email: veronicaw33@yahoo.com
}

\section{Resumen}

En este trabajo presentamos el estudio de las primeras evidencias de producción metalúrgica recuperadas a partir de investigaciones llevadas adelante en el asentamiento de Tacuil, asignable al Período Tardío-Inca, localizado en las quebradas altas del valle Calchaquí medio, Salta. Dichas evidencias consisten en fragmentos de cerámica metalúrgica (moldes, crisoles e intermediarios) como también en fragmentos de metal. Los análisis morfológicos y de caracterización de composición realizados sobre las piezas dan cuenta de la serie de operaciones involucradas en la actividad metalúrgica desarrollada en el sitio: fundición de minerales de cobre o cobre metálico, empleo de aleación de bronce estañífero, producción de objetos del repertorio común al Período Tardío en el Noroeste Argentino (posibles cinceles, hachas en T, hachas planas) y el uso de sustancia blanquecina (principalmente compuesta por calcio y fósforo) para facilitar el desmolde y minimizar irregularidades en las superficies de los objetos de metal elaborados. Se observa a su vez en este proceso la estrecha vinculación entre las tradiciones de producción cerámica y metalúrgica. Discutiremos dichos resultados integrándolos con los antecedentes de investigación de regiones aledañas.

Palabras clave: valle Calchaquí medio, Período Tardío e Inca, producción cerámica y metalúrgica.

\begin{abstract}
This paper presents the analysis of the first pieces of evidence of metallurgical production recovered during the study carried out in the settlement of Tacuil, dated from Late-Inca period, located in the middle-high Valle Calchaquí, Salta. These samples are fragments of metallurgical ceramics (moulds, crucibles, and intermediaries) and pieces of metal. The morphological analysis and compositional characterization of these pieces of evidence show the set of operations involved in the metallurgical activity carried out in the site: smelting of copper minerals or metallic copper, use of bronze (copper-tin alloy), manufacture of objects from the common repertoire of Late period in the Northwest of Argentina (possible chisels, T-axes and plain axes) and the employment of a white substance (mainly made of calcium and phosphorous) to facilitate unmolding and to minimize irregularities in the surfaces of the produced metal objects. It is clear to see the close link between the traditions of ceramic and metallurgical production. These analytical results are discussed, integrating them with the previous pieces of research developed in neighboring regions.
\end{abstract}

Keywords: Middle Calchaquí valley, Late-Inca period, ceramic and metallurgical production.

Recibido: 31 octubre 2017. Aceptado: 7 enero 2020. 


\section{Introducción}

Diferentes especialistas han señalado que la tecnología metalúrgica estuvo asociada a la política y al despliegue de mensajes ideológicos en los Andes (Lechtman, 1988, 1991); entendiéndola, además, como un proceso cultural que se enmarca en un determinado contexto social (González, 2004). En este sentido, en los últimos 40 años se ha dado importancia al estudio de los pasos fundamentales precedentes a la manufactura del objeto de metal en sí mismo (extracción y procesamiento de minerales, preparación de combustible, fundición, etc.) y a la articulación de la metalurgia con otros aspectos de la tecnología y la cultura andina, diferenciándose de previos enfoques que se habían centrado únicamente en el estudio analítico de los objetos metálicos recuperados (Lechtman, 1976; González, 2004).

En el caso de las investigaciones acerca de la metalurgia en el Noroeste Argentino (en adelante NOA), las mismas han aportado importantes datos que permiten discutir el desarrollo de esta práctica no solo desde un enfoque tecnológico sino, y principalmente, desde aspectos sociales. A los trabajos pioneros de A. Rex González (1979, 1992), debemos sumar investigaciones realizadas en sitios del valle de Yocavil (Tarragó y González, 1998; González y Gluzman, 2007; González, 2010; Gluzman, 2011; entre otros), en Hualfín (Raffino, 1983; Scattolin y Williams, 1992; Giovannetti et al., 2015), en Quebrada de Humahuaca (Angiorama, 2003, 2006, 2011), o en los valles orientales salteńos (Ventura y Scambato, 2013), entre otras.

Dichos trabajos han remarcado el desarrollo de la máxima expresión de la tradición metalúrgica en el NOA durante el Período Tardío o Período de Desarrollos Regionales (González, 2004; Angiorama, 2011), con el manejo del bronce estañífero para la elaboración de piezas utilitarias y de otras como placas de bronce, campanas ovales y hachas con mango incorporado, que se constituyeron en símbolos de ceremonialismo (González, 2004, 2010). Dentro de este marco, se ha puesto énfasis en las variaciones en la organización y producción metalúrgica a nivel regional (González, 2004; Angiorama, 2011; Gluzman, 2011; Raffino, Gobbo, Iácona y Moralejo, 2015; entre otros).
Se ha postulado que uno de los intereses de la expansión del Estado inca en el NOA estuvo vinculado con la minería y las tradiciones metalúrgicas en la región (Raffino, 1983; González, 1992). En este sentido, la conquista del territorio y la explotación de los recursos minerales implicaron una configuración del espacio donde minas y montañas eran consideradas wak'as poderosas y por tanto, se ha observado en ciertos espacios una clara vinculación entre sitios mineros y evidencias de prácticas de culto a los cerros (Cruz, 2013). Se ha planteado que a partir de la dominación inca más que importantes cambios tecnológicos metalúrgicos se originaron una serie de modificaciones en la organización de la producción de metales, dada por el control imperial de las actividades, por el aumento de la escala de producción, por la ampliación y reasignación de los espacios dedicados a dichas tareas, por la aplicación de estructuras de fundición masiva tipo huayra, por la demanda de lingotes de metal de diferentes tamańos y por la introducción de objetos nuevos al repertorio local (González, 2002). Por otra parte, el Estado habría regulado también el acceso a las fuentes de mineral (Angiorama, 2011). En otros casos, sin embargo, se ha identificado la continuidad de prácticas metalúrgicas por fuera de la órbita estatal (Zagorodny, Angiorama, Becerra y Pérez Pieroni, 2015).

Para los valles Calchaquíes, en particular, se cuenta con información específica sobre objetos de metal en la obra de Ambrosetti (1904, p. 171), titulada El bronce en la región Calchaquí, donde se menciona el hallazgo de piezas en distintas localidades del valle como Cachi, Luracatao, Molinos, Cafayate, entre otros. Hasta el momento, no contábamos con evidencia de producción metalúrgica en las quebradas altas del Calchaquí. Los trabajos de investigación llevados adelante en el asentamiento de Tacuil, asignable al Período Tardío o de Desarrollos Regionales (en adelante PDR) e Inca, entre el 900 y 1500 DC aproximadamente, localizado en la cabecera sudoccidental de la quebrada del río Tacuil, en las quebradas altas del valle Calchaquí medio, Salta, Argentina (Figura 1), han permitido recuperar una serie de evidencias vinculadas con el desarrollo de actividades metalúrgicas, como diversos tipos de cerámica refractaria y fragmentos de metal. El objetivo de este trabajo es dar a conocer los resultados obtenidos a partir del 
estudio de dicha evidencia para sumar información al conocimiento de la producción metalúrgica en la zona. Presentaremos, entonces, los análisis morfológicos y de caracterización de composición realizada, dando cuenta así de la serie de operaciones involucradas en la actividad desarrollada en el sitio e integrando los resultados con los antecedentes de investigación de regiones aledañas.

\section{El contexto regional: las quebradas altas del valle Calchaquí medio durante el Período Tardío-Inca}

Se ha planteado que la ocupación de los asentamientos nucleados o conglomerados en el sector medio del valle Calchaquí se habría iniciado hacia los siglos IX-X DC en sitios como Molinos 1 (Baldini,

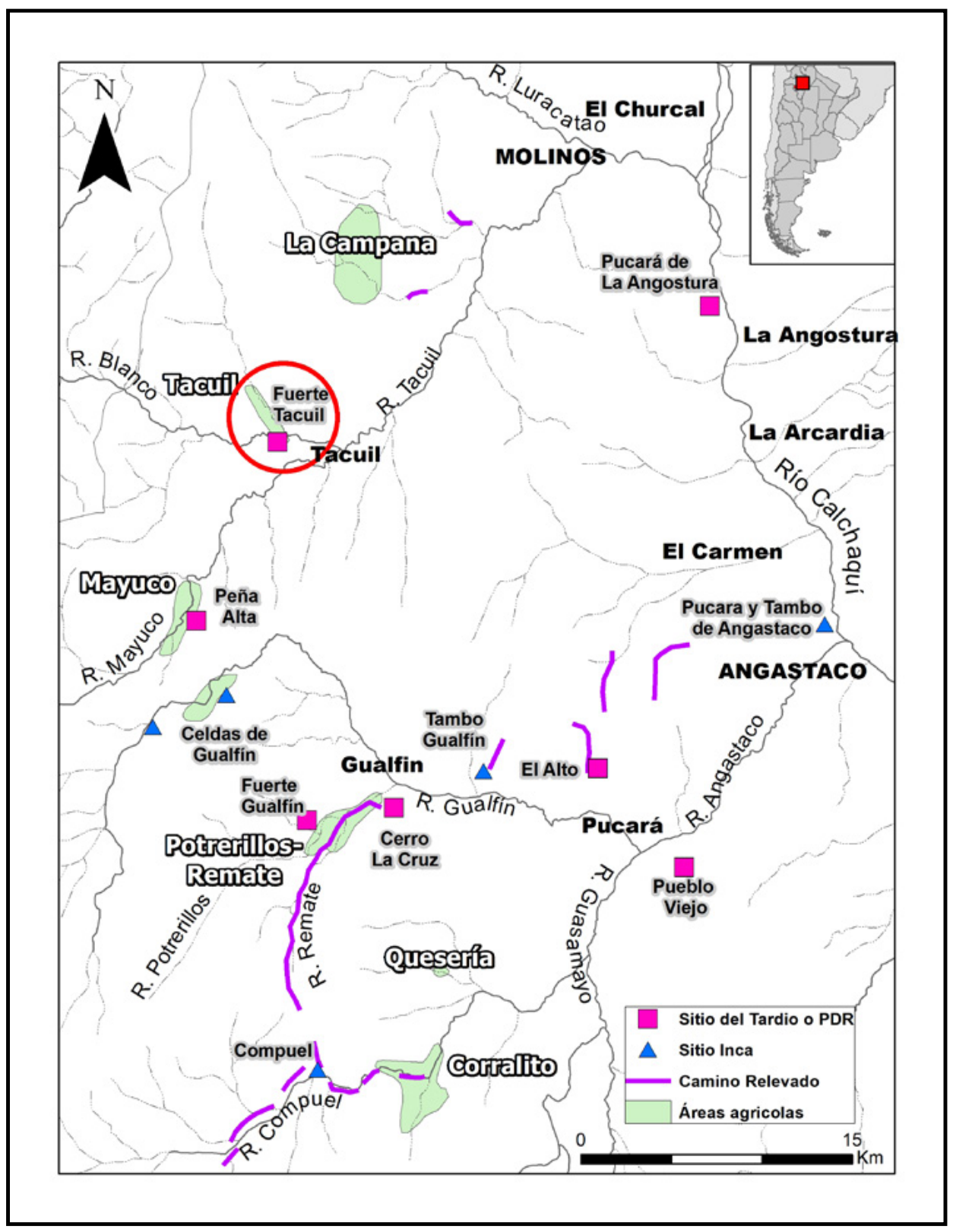

Figura 1. Mapa del área de trabajo en las quebradas altas del valle Calchaquí medio (Salta, Argentina), con sitios registrados y mencionados en el texto. Tomado y modificado de Villegas (2014, p. 37). 
2003). Para momentos posteriores, Baldini y Villamayor (2007) proponen una concentración poblacional sobre el valle principal. En las quebradas altas o subsidiarias, entre los 2600 y $3400 \mathrm{msnm}$, habría predominado un modo de asentamiento de carácter rural, al que se asocian escasos poblados concentrados y de carácter defensivo (Baldini y Villamayor, 2007, p. 37). Estas quebradas son vías naturales de comunicación con la puna de las actuales provincias de Salta y Catamarca; vinculando los valles Calchaquíes con el salar de Diablillos, el cerro Blanco, a la altura de Colomé, y el cerro Gordo, en las nacientes del río Tacuil-Amaicha (Baldini, 2003; Williams, 2010; Williams y Villegas, 2013). Pero además, permiten la conexión con Antofagasta de la Sierra, en la actual puna catamarqueña, y con sectores más alejados como el norte de Chile; siendo las vías que siguieron viajeros y naturalistas hacia fines del siglo XIX (Bertrand, 1885; Philippi, 1860; Holmberg, 1900).

En el interior de las quebradas altas hasta el momento se han localizado alrededor de 25 sitios habitacionales, entre ellos nueve pukaras, algunos conjuntos arquitectónicos pequeños menores a 2 ha, además de grandes extensiones de cultivo que superan las 500 ha (Villegas, 2014; Williams, 2010). Los pukaras se emplazan en lugares estratégicos, con muy buena visibilidad, asociados a espacios de tránsito y a asentamientos agrícolas (Williams, 2010; Villegas, 2014). Los fechados radiocarbónicos de estos sitios permiten sugerir una ocupación que se extendería desde los inicios del PDR (siglo X) hasta, por lo menos, mediados del siglo XVII, cuando toman protagonismo en las narrativas históricas sobre los levantamientos indígenas del valle (Williams, 2015).

En cuanto a la metalurgia de la región, como mencionamos, las primeras informaciones sobre la presencia de objetos de metal en Calchaquí en la actual provincia de Salta provienen de Ambrosetti (1904), quien refiere su hallazgo en diferentes sitios y además incorpora datos de fuentes documentales y análisis químicos sobre piezas completas. Objetos metálicos como anillos, discos, pinzas, punzones, placas, entre otros, procedentes del sitio La Paya, en el Calchaquí norte, han sido inicialmente trabajados por Ambrosetti (1907) y, posteriormente, también analizados por Sprovieri (2013).
Para el sitio de Molinos I, emplazado en el sector medio y sobre fondo de valle, Lidia Baldini registró evidencias de actividades metalúrgicas entre las que se destacan un área de combustión, un objeto de metal, un molde y roca de molienda con rastros de mineral de cobre (Baldini, 1992). El análisis composicional de un adorno metálico de este sitio evidenció el uso de una aleación de cobre y estaño (Baldini, 1996, citado en Sprovieri, 2013, p. 103). En este sector, para El Churcal, Rodolfo Raffino menciona el hallazgo de un cincel de bronce, pinzas de depilar y tumis (Raffino, 1984, p. 249).

También tenemos noticias del hallazgo de piezas metálicas, como hachas en $\mathrm{T}$, en los alrededores del pukara de Angastaco y en el mismo Tacuil (Raffino, 1981, p. 187). Asimismo, en el Catálogo de la Colección Zavaleta (1906) se hace mención a una importante cantidad de piezas recuperadas en este último sitio, en Molinos y Luracatao (Palamarczuk, 2011; Castellanos y Becerra, 2019). Lamentablemente no tenemos datos exactos sobre la procedencia de los materiales, aunque suponemos se trataría de ofrendas funerarias. ${ }^{1}$

Destacamos, por otra parte, la presencia de un $m a-$ ray en la actual Sala de la finca Tacuil y la potencial funcionalidad como hornos de unas estructuras circulares registradas en el pukara de Angastaco (Williams, Villegas, Gheggi y Chaparro, 2005).

\section{El caso de Tacuil: el pukara y los recintos bajos}

En la actual finca de Tacuil, a $35 \mathrm{~km}$ hacia el oeste del actual pueblo de Molinos, provincia de Salta, y a $2728 \mathrm{msnm}$, se registran conjuntos arquitectónicos emplazados en dos farallones de ignimbrita, a aproximadamente $100 \mathrm{~m}$ de distancia. En uno de ellos se emplaza el pukara o Fuerte de Tacuil y en el otro

1 En la actualidad, parte de la Colección Zavaleta se encuentra en el Field Museum of Natural History de Chicago, en el Museo Etnológico de Berlín (Ethnologisches Museum), además del Museo Etnográfico "Juan B. Ambrosetti” (FFyL, UBA) y el Museo Arqueológico Eduardo Casanova (Tilcara) (FFyL, UBA). También tenemos datos de que el Museo de La Plata realizó una compra de esta colección hacia 1888 (Castellanos y Becerra, 2019). 


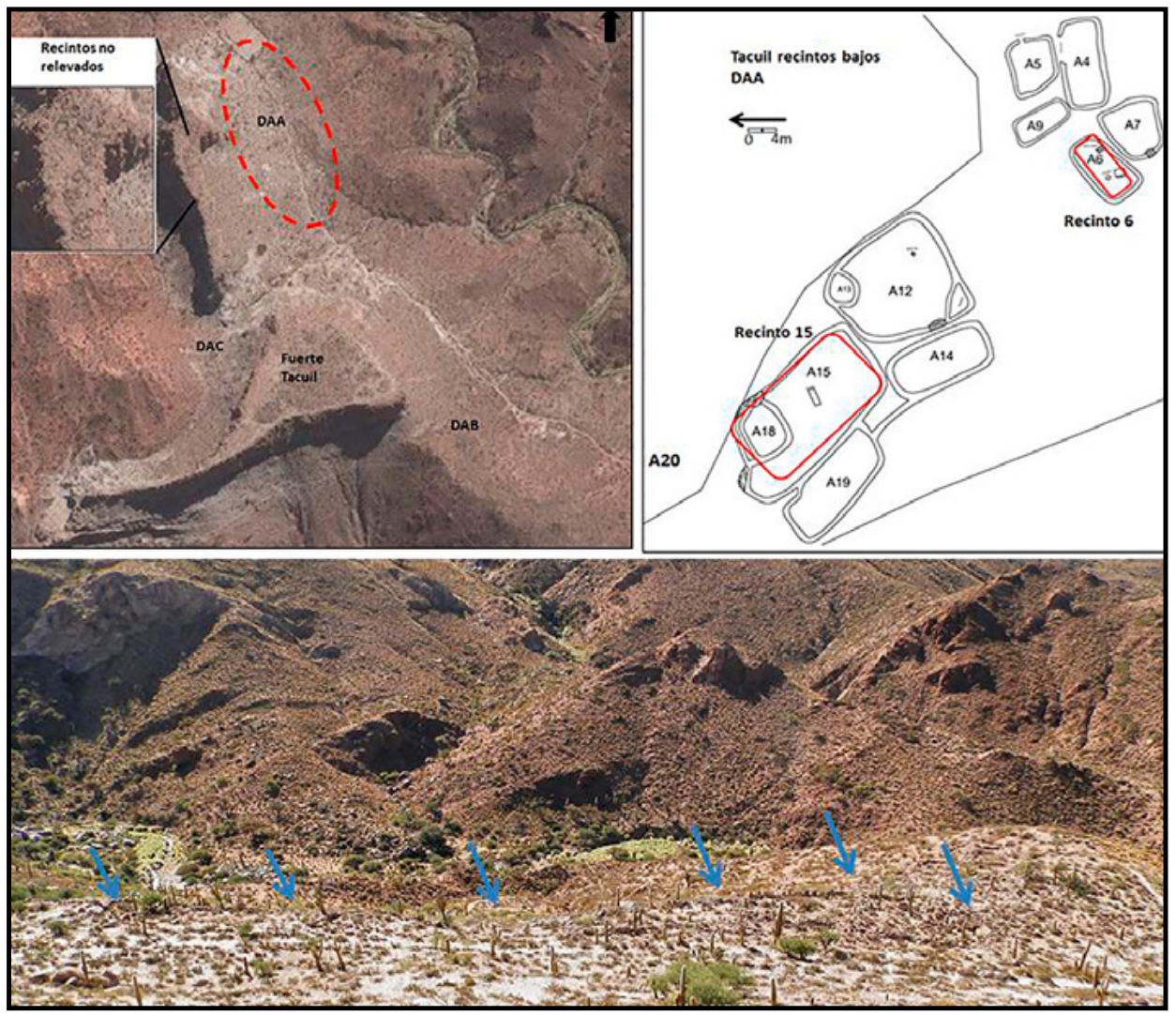

Figura 2. Arriba izquierda: vista general del pukara de Tacuil y los recintos bajos asociados (Modificado de Bingmaps). Arriba derecha: plano de los recintos bajos, DAA (Imagen cedida por Orsini y Benozzi 2016). Abajo: vista general de la DAA (Imagen de las autoras).

farallón, localizado hacia el noroeste, se pudieron detectar por medio de fotografías aéreas una serie de recintos que todavía no fueron relevados (Figura 2). Para este espacio, Villegas (2014) ha reconocido 11 sectores con infraestructura agrícola que representan un total de 15,1 ha.

El pukara o fuerte se encuentra en la cabecera sudoccidental de la quebrada del río homónimo, a 25³4'17,9" latitud sur y 66²8'30,6" longitud oeste, sobre una meseta dacítica de origen volcánico cuyo acceso es sumamente difícil, con una pendiente de casi $80^{\circ}$ (Villegas, 2014). El mismo fue dado a conocer a mediados de los años setenta por Rodolfo Raffino y Eduardo Cigliano (Cigliano y Raffino, 1975). Este asentamiento es el pukara más septentrional de las quebradas altas, situado en la confluencia de los ríos La Hoyada y Blanco, afluentes del río Tacuil. Desde su localización se cuenta con un dominio visual sobre la confluencia de los ríos Blanco y La Hoyada, asociados a las abras de los cerros Gordo y Blanco, pasos naturales hacia la puna (Villegas, 2011).

$\mathrm{Al}$ pie de este asentamiento se emplazan conjuntos de estructuras que conforman pequeños semiconglomerados llamados Divisiones Arquitectónicas A, $\mathrm{B}$ y C; de una de ellas (DAA) provienen los materiales analizados en este trabajo. La misma presenta estructuras aparentemente habitacionales, patios, posibles morteros y bloques con motivos abstractos de líneas serpenteantes unidas a depresiones circulares u ovoidales, cochas o cúpulas, también denominados como maquetas (Williams y Castellanos, 2018).

Es interesante destacar que en sitios mineros incaicos y coloniales del altiplano boliviano se identificaron representaciones rupestres caracterizadas por 


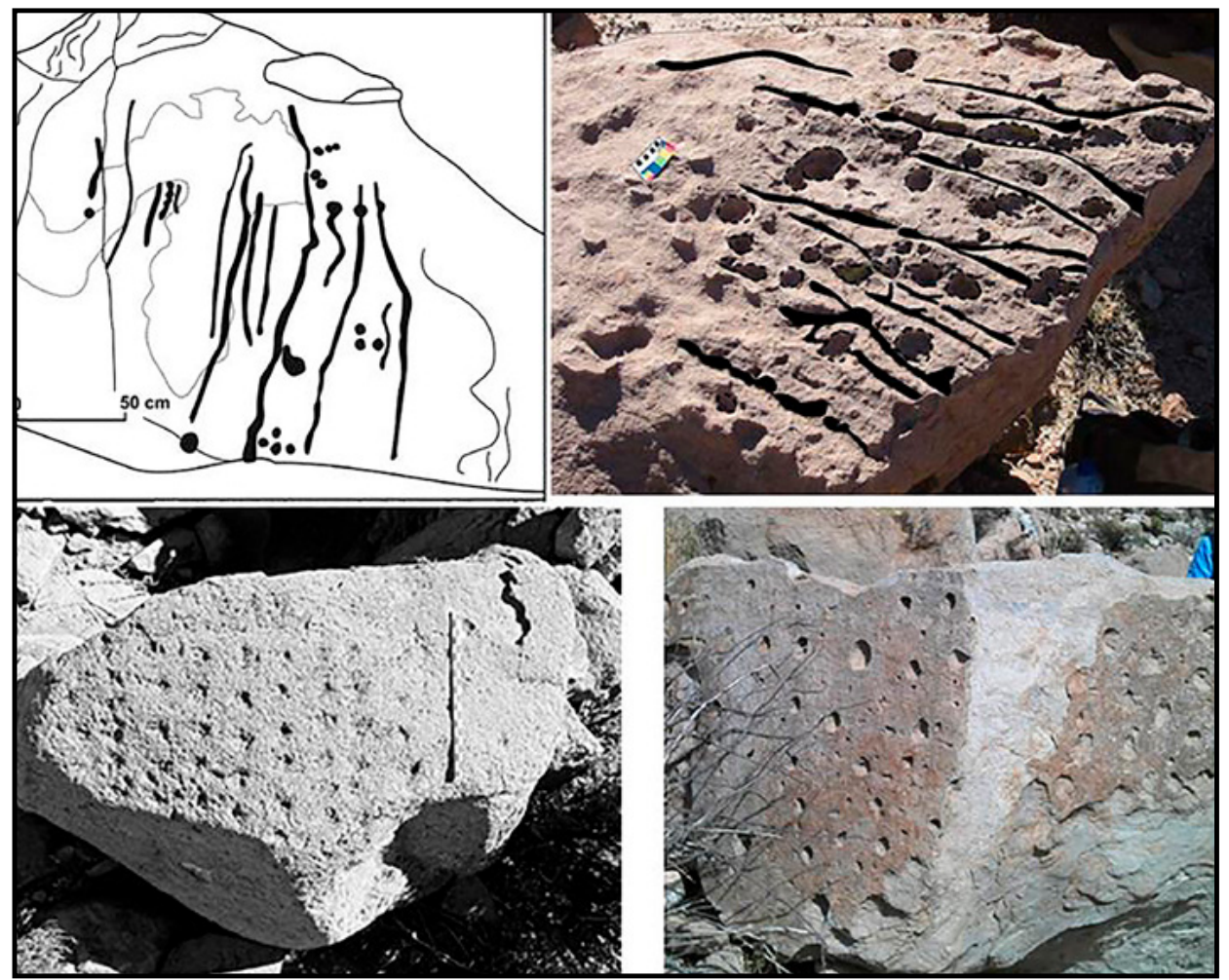

Figura 3. Arriba: rocas con grabados de líneas serpentiformes y cúpulas en Pukara de Alianza, región Intersalar (Tomado de Cruz, 2015, p. 69) y bloque con cochas y líneas serpenteantes de Tacuil (Fotografía tomada por V. Williams). Abajo: bloque con cúpulas, región intersalar, Pukara de Alianza (Tomado de Cruz, 2015, p. 69). Derecha: bloque con cúpulas en la base del Pukara de Tacuil (Fotografía tomada por V. Williams).

líneas serpenteantes, horadados y cúpulas similares a las observadas aquí, en asociación con montañas sacralizadas, áreas agrícolas y espacios con explotaciones mineras (Cruz, 2015) (Figura 3).

En la DAA hemos podido definir un número de 54 estructuras y realizar sondeos exploratorios en tres (núms. 6, 15 y 20) con el fin de conocer la estratigrafía de las mismas, obtener material fechable y lograr una primera aproximación sobre las actividades desarrolladas en este sitio. En esta oportunidad nos referiremos a los materiales recuperados en las estructuras núms. 6 y 15 (ver Figura 2). En general se trata de recintos rectangulares y subrectangulares de muros dobles y bordes redondeados, algunos de los cuales comparten muros y presentan un pasillo o espacio de ingreso. Hacia el sector este del semiconglomerado y bordeando el área se localizan recintos circulares, emplazados generalmente en pares, los cuales interpretamos como tumbas tipo cista. Los mismos presentan un diámetro aproximado de 1,80 $\mathrm{m}$ y muros dobles con argamasa, contándose un número de 11. Actualmente presentan señales de haber sido excavados con anterioridad, ${ }^{2}$ hallándose en los alrededores abundantes fragmentos de piezas cerámicas y, en algunas de ellas, cuentas y pequeños fragmentos de metal.

Recientemente se realizaron tres fechados absolutos sobre muestras de carbón tomadas en dos recintos subrectangulares del conjunto (núms. 15 y 20). Los resultados son coincidentes con el fechado que tenemos para el pukara, asignando su ocupación durante el PDR o Tardío (Williams, 2019) (Tabla 1).

2 Es importante señalar que, hacia fines de 1800, Manuel Zavaleta pasó por este asentamiento excavando de manera informal tumbas y recolectando abundante material que conformaría luego la colección privada ya mencionada. 
Aproximación a la tecnología cerámica y metalúrgica en las quebradas altas del Noroeste Argentino: el caso de Tacuil...

Tabla 1. Fechados radiocarbónicos de los sitios Fuerte o Pukara de Tacuil y Tacuil recintos bajos.

\begin{tabular}{|l|c|c|c|c|}
\hline Código muestra & ${ }^{14} \mathbf{C}$ años AP & Cal 2 $\boldsymbol{\sigma}$ AC & Material & No laboratorio \\
\hline FTacDAAR1S1N2T5 & $630+/-25 \mathrm{BP}$ & $1311-1413 \mathrm{AD}$ & Carbón & UGA 5939 \\
\hline TACRBDAAR20 N6 T2 & $590+/-30 \mathrm{BP}$ & $1290-1420 \mathrm{AD}$ & Carbón & IDA $18 \mathrm{C} / 0767$ \\
\hline TACRBDAAR15 C2N12H2 & $760+/-30 \mathrm{BP}$ & $1210-1290 \mathrm{AD}$ & Carbón & $18 \mathrm{C} / 0768$ \\
\hline TACRBDAAR15C2N16H1 & $610+/-30 \mathrm{BP}$ & $1290-1410 \mathrm{AD}$ & Carbón & $18 \mathrm{C} / 0769$ \\
\hline
\end{tabular}

Fuente: Tomado de Williams (2019).

La cerámica hallada en superficie y en estratigrafía, en mayor cantidad el estilo Santa María, estilos Belén Inca y Santamariano Valle Arriba, ${ }^{3}$ y el registro de piezas de metal en Tacuil como los tumis de la Colección Zavaleta (Castellanos y Becerra, 2019) apoyan la idea de una ocupación durante el Tardío o PDR e Inca. Otras evidencias que sustentan esta cronología se asocian a bloques con maquetas y grabados, lo cual ha llevado a postular entre las estrategias de expansión estatal una vinculada a la apropiación de espacios con ocupación previa (Williams y Villegas, 2013, 2017).

En otros sectores de las quebradas altas del Calchaquí medio, lo inca se hace evidente a partir del emplazamiento de asentamientos como pukaras, tambos, tramos de infraestructura vial, grandes extensiones agrícolas y recintos de tipo celdas, los cuales se localizan -principalmente- hacia el sur de Tacuil, a la altura de la localidad de Pukara y Tambo de Angastaco (Williams, 2015).

Recientes trabajos de prospección realizados en un área que une la localidad de Tacuil con el abra del cerro Blanco, en la puna, han permitido registrar una serie de sitios agrícolas, al menos dos tambos y un posible chasquiwasi, asociados a tramos de ca-

3 La subtradición Valle Arriba del estilo Santa María ha sido definida como tal por Serrano (1958) para el sector sur del valle Calchaquí y caracterizada por la presencia de representaciones de un ave bicéfala de frente con alas replegadas y un cuerpo triangular o con las alas extendidas y la cabeza replegada; el ave bicéfala triangular desintegrada en sus dos mitades o una serpiente bicéfala (Serrano, 1958, p. 63). El hallazgo en un contexto de entierro múltiple del Tardío-Inca en la zona de Payogastilla, al sur de Angastaco, dio a lugar al planteo de la hipótesis de que esta subtradición podría estar representando una Fase Inca (sensu Calderari y Williams, 1990) para el sur del valle Calchaquí (Vasvari, 2014, p. 83). mino (Kevin Lane, com. pers., 6 de octubre, 2017). Esto da cuenta de una ocupación estatal mucho más amplia de lo que hasta el momento teníamos registrado para este sector de las quebradas altas.

Los trabajos de campo realizados en el año 2015 en la DAA de los recintos bajos de Tacuil permitieron recuperar 28 materiales cerámicos refractarios (23 de superficie y 5 de excavación) y nueve líticos posiblemente asociados a la producción metalúrgica. ${ }^{4}$ Las muestras recolectadas de superficie provienen de un sector al que denominamos como Ladera este, donde además se hallaron materiales líticos como morteros, manos y rocas con evidencia de desgaste por uso. También se hallaron dos fragmentos muy pequeños de metal en superficie, próximos a la tumba tipo cista $\mathrm{C}$ y en el sector donde se hallaban los refractarios (Castellanos, 2017). Hasta el momento no hemos localizado hornos o estructuras que puedan asociarse a la fundición, aunque recién estamos iniciando los trabajos en los recintos bajos, por lo cual no descartamos que a futuro se puedan agregar nuevos datos.

\section{El análisis de las evidencias de producción metalúrgica de los recintos bajos de Tacuil}

Como hemos mencionado, las evidencias de producción metalúrgica recuperadas en el sitio consisten en dos fragmentos de metal y 28 fragmentos de refractarios, algunos de los cuales presentan residuos metálicos adheridos a sus paredes. Las cerámicas refractarias, técnicas (Martinón-Torres y Rehren, 2014) o metalúrgicas (Gluzman, 2015) son cerámicas manufacturadas para ser empleadas

4 Actualmente se hallan en proceso de análisis a cargo de Erico Gaál, miembro del equipo dirigido por V. Williams. 
en operaciones metalúrgicas, ya sea como contenedores de dichos procesos o como intermediarios. Con estos conceptos se las diferencia de otras tecnologías cerámicas, ya que para ser funcionales estas cerámicas metalúrgicas deben soportar temperaturas de hasta 1000 o $1200{ }^{\circ} \mathrm{C} \mathrm{y}$, por tanto, presentar ciertas capacidades físicas (fortaleza mecánica, resistencia al shock térmico y propiedades refractarias térmicas) (Martinón-Torres y Rehren, 2014). Además de las formas diferentes (de acuerdo a su función), una de las características de estas piezas es la presencia de adherencias de metal en las superficies o en la pasta y, en el caso de las recuperadas en el NOA, la aplicación de una sustancia blanquecina en la superficie. También se ha observado la deformación y/o vitrificación de las pastas por el sometimiento a calor excesivo, una matriz porosa y la importante cantidad de antiplásticos en pastas, además de alteraciones en la tonalidad de la pasta por sobrecocido y/o reducción (González, 2004; Gluzman, 2015).

Desde lo morfológico, las cerámicas metalúrgicas halladas en los recintos bajos de Tacuil se pueden agrupar en tres categorías, de acuerdo a la clasificación de González (2004) (Figura 4). Cada una de ellas difiere en forma, función y según las distintas etapas de la producción metalúrgica en las que participan.

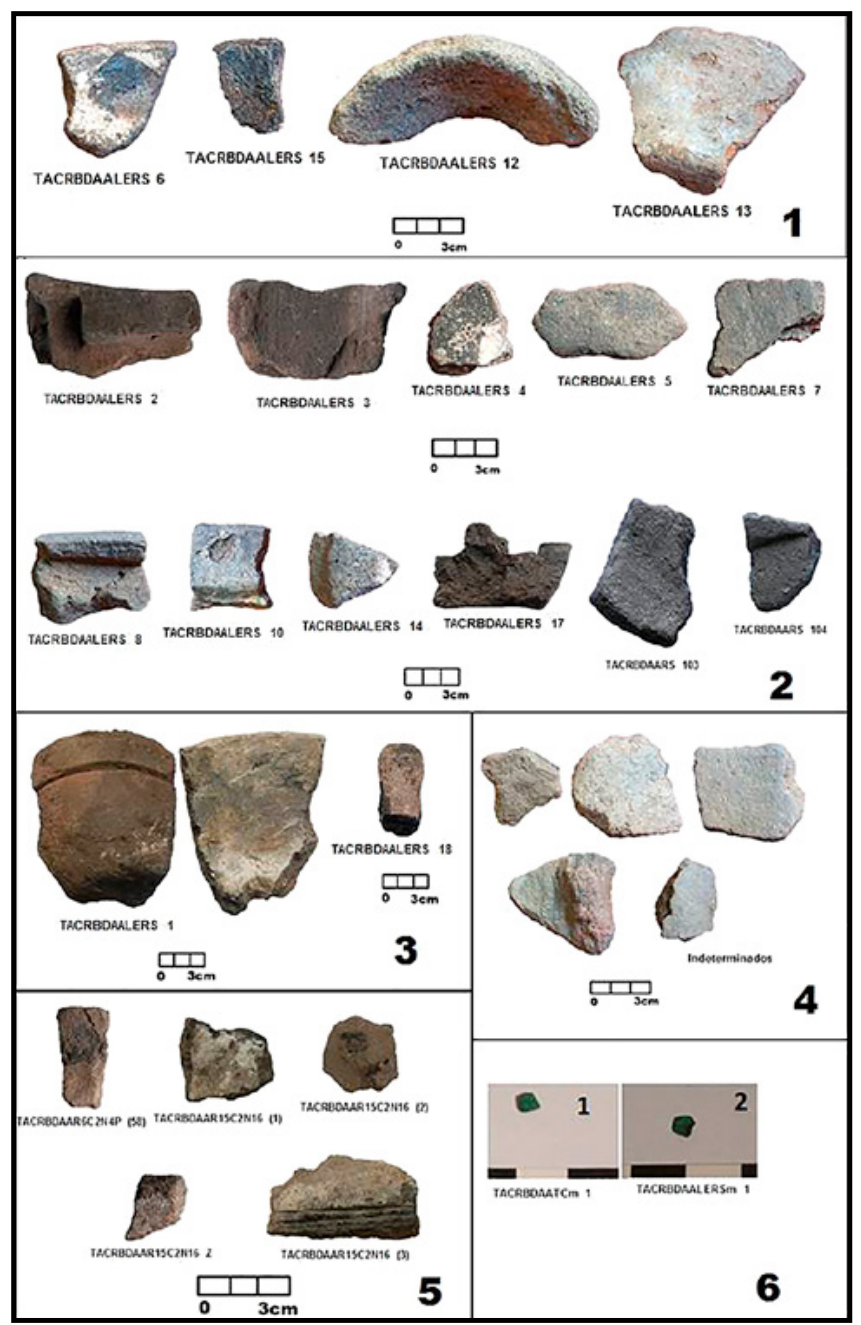

Figura 4. Tipos morfológicos de refractarios cerámicos recuperados en los recintos bajos de la DAA de Tacuil. 1: crisoles. 2: moldes. 3: intermediarios. 4: indeterminados. 5: fragmentos de moldes recuperados en recintos 6 y 15. 6: fragmentos metálicos. (Imágenes de las autoras). 
Tabla 2. Grupo de fragmentos de crisoles de los recintos bajos de Tacuil, DAA.

Características tecno-morfológicas, métricas, tipo de cocción y pasta.

\begin{tabular}{|c|c|}
\hline Fragmentos de crisoles & Características morfológicas y tecnológicas. Medidas. Tipo de pasta \\
\hline TACRBDAALERS 6 & $\begin{array}{l}\text { Fragmento de cuerpo y borde (tipo bisel). Tratamiento de superficie: alisado irregular. Cocción } \\
\text { no oxidante irregular. Evidencias de exposición a fuego. Medidas: No es posible estimar diámetro. } \\
\text { Altura del fragmento } 48 \mathrm{~mm} \text {, ancho } 51 \mathrm{~mm} \text {. Espesor de paredes: borde } 10 \mathrm{~mm} \text {, cuerpo } 15 \mathrm{~mm} \text {. Sobre } \\
\text { la superficie interna presenta residuos de color negro adheridos a las paredes posiblemente se trate de } \\
\text { metal entrampado y, en algunos sectores, una pátina blanca. Tipo de pasta: Aspecto compacto, textura } \\
\text { porosa, fractura irregular. Inclusiones: cuarzos, litoclastos grises y negros, muscovita de tamaño muy } \\
\text { pequeño. Cavidades redondeadas, pequeñas. }\end{array}$ \\
\hline TACRBDAALERS 12 & $\begin{array}{l}\text { Parte de la superficie de apoyo y una pequeńa porción de paredes. Tratamiento de superficie: alisado } \\
\text { irregular. Cocción bajo atmósfera oxidante irregular. Medidas: Altura } 53 \mathrm{~mm} \text {. Espesor en paredes } \\
17 \mathrm{~mm} \text {, en superficie de apoyo } 27 \mathrm{~mm} \text {. Diámetro } 11,6 \mathrm{~cm} \text {. No se observa residuo en las superficies } \\
\text { pero sí una diferencia de color por exposición al calor. Pasta compacta, textura compacta y porosa, } \\
\text { fractura irregular (desgranable). Pequeñas cavidades redondeadas. Inclusiones: muscovitas, cuarzos y } \\
\text { posiblemente plagioclasas. }\end{array}$ \\
\hline TACRBDAALERS 13 & $\begin{array}{l}\text { Fragmento de posible crisol (parte de base, cuerpo y borde). Labio plano irregular. Tratamiento de } \\
\text { superficie alisado irregular. Cocción oxidante irregular. Medidas: Altura } 65 \mathrm{~mm} \text {, espesor pared de } \\
\text { borde } 11 \mathrm{~mm} \text {, espesor pared cuerpo } 13 \mathrm{~mm} \text {, espesor base } 21 \mathrm{~mm} \text {. Diámetro estimado: } 12 \mathrm{~cm} \text {. Sobre la } \\
\text { superficie interna se presenta residuo blanco en sector cercano al borde. Pasta de aspecto compacto, } \\
\text { textura compacta, fractura irregular. Inclusiones: cuarzo, litoclastos grises, muscovita, de tamaño } \\
\text { pequeño. }\end{array}$ \\
\hline TACRBDAALERS 15 & $\begin{array}{l}\text { Fragmento posible crisol (parte de cuerpo y borde plano y en algunos sectores redondeado. } \\
\text { Tratamiento de superficie alisado irregular. Cocción oxidante irregular (superficies termo-alteradas). } \\
\text { Medidas: } 29 \mathrm{~mm} \text { de ancho, } 37 \mathrm{~mm} \text { de altura, espesor de borde } 17 \mathrm{~mm} \text {, espesor de cuerpo } 14 \mathrm{~cm} \text {. } \\
\text { Medidas: Sobre la superficie interna se puede observar la presencia de residuos, evidencias de } \\
\text { vitrificado y restos de pátina blanca. Pasta compacta, textura compacta/porosa, fractura irregular } \\
\text { (desgranable). Cavidades redondeadas. Inclusiones: cuarzos, litoclastos negros y grises. }\end{array}$ \\
\hline
\end{tabular}

1) Crisoles: se denomina así a contenedores con bocas ovaladas o circulares, paredes gruesas (que facilitaban la resistencia al shock térmico); algunos presentaban un sistema de agarre para su manipulación. Fueron utilizados en tareas de fundición o para contener minerales donde se podía agregar también carbón vegetal para inducir la reducción química.

En Tacuil se recuperaron fragmentos de sectores de bordes, sin canal perimetral, y partes de cuerpos. Han sido agrupados en esta categoría teniendo en cuenta indicadores como espesor de pared y características del borde (Tabla 2). En tres casos ${ }^{5}$ (TACRBDAALERS 6, 13 y 15) se presentan adherencias de color blanquecino en la superficie interna y en dos de ellos (TACRBDAALERS 6 y 15) se encuentran

5 Los fragmentos de refractarios han sido nombrados mediante la sigla TAC (Tacuil), RB (recintos bajos), DAA (División Arquitectónica A), LE (ladera este), RS (recolección de superficie), continuado de una numeración consecutiva iniciada en el número 1. residuos de metal entrampado en las paredes y evidencias de sectores vitrificados. En el siguiente apartado nos referiremos a los análisis realizados sobre estos residuos.

2) Moldes: son artefactos donde se vierte el metal fundido para que solidifique en la forma deseada. Pueden ser abiertos, cerrados, de dos o más valvas, según el tipo de pieza que se desea obtener.

En este caso, se recuperaron fragmentos de moldes de vaciado (sin borde o tapa de molde bivalvo, con borde pequeño y escaso espesor de la pieza, con gran reborde, con esquinas redondeadas, con curvatura pronunciada, con esquina recta y mucha profundidad) y uno de doble uso (TACRBDAALERS 2) (Gluzman, 2011), ya que presenta concavidades en ambas caras (Tabla 3). En este caso, las formas de las mismas nos indican que habrían sido empleadas en la manufactura de hachas en $\mathrm{T}$, observándose en una de las caras una de tamaño 
mayor que la de la superficie contraria. En el caso del resto de los moldes, las formas y dimensiones observadas a pesar de la fragmentación nos sugieren que podrían haber sido empleados para la manufactura de hojas como las de las denominadas hachas planas (Ambrosetti, 1904; Mayer, 1986) (TACRBDAALERS 3) y posibles cinceles o barras (TACRBDAALERS 17). En el resto de los casos no podemos distinguir la morfología del objeto deseado, aunque debemos destacar que en el caso de los moldes TACRBDAALERS 4 y 14 se observa en la concavidad un sector de borde redondeado; y nos preguntamos si puede corresponder a una pieza que presente una forma cóncava, quizás un disco o el cabezal de un topu. Asimismo, en cinco fragmentos se observa la presencia de una pátina blanquecina en una de sus superficies y en cuatro de ellos, de metal entrampado.

Tabla 3. Grupo de fragmentos de moldes de los recintos bajos de Tacuil, DAA.

Características tecno-morfológicas, métricas, tipo de cocción y pasta.

\begin{tabular}{|c|c|}
\hline Fragmentos de moldes & Características morfológicas y tecnológicas. Medidas. Pasta \\
\hline TACRBDAALERS 2 & $\begin{array}{l}\text { Cuerpo de molde doble. En ambas superficies se observa la forma de un hacha en T, siendo una de } \\
\text { ellas de mayor tamańo. La porción del molde corresponde al sector distal del hacha. } \\
\text { Medidas del molde completo: espesor total } 31 \mathrm{~mm} \text {, largo total } 73 \mathrm{~mm} \text {, ancho mayor } 45 \mathrm{~mm} \text { y ancho } \\
\text { menor } 28 \mathrm{~mm} \text {. Medidas del molde de hacha grande } 64 \mathrm{~mm} \text { de largo, } 28 \mathrm{~mm} \text { de ancho. Profundidad } \\
11 \mathrm{~mm} \text {. Medidas del hacha menor: } 15 \mathrm{~mm} \text { de largo por } 10 \text { de ancho, } 6 \mathrm{~mm} \text { de profundidad. En ambos } \\
\text { casos se observan sectores con un residuo blanquecino siendo más evidente en el molde de mayor } \\
\text { tamańo. Textura compacta, escasas cavidades muy pequeñas. Inclusiones muy pequeńas y escasas: } \\
\text { cuarzos, feldespatos y muscovita. }\end{array}$ \\
\hline TACRBDAALERS 3 & $\begin{array}{l}\text { Base y parte del cuerpo de base de un molde de una posible hacha plana. Superficie interna alisada, } \\
\text { siendo el sector del borde plano. Cocción oxidante irregular. Medidas: espesor en cuerpo } 22 \mathrm{~mm} \text {, en } \\
\text { sector de paredes } 34 \mathrm{~mm} \text {, ancho del molde } 74 \mathrm{~mm} \text {, largo } 44 \mathrm{~mm} \text {, profundidad } 11 \mathrm{~mm} \text {. Pasta de aspecto } \\
\text { compacto, textura porosa, fina, fractura terrosa. Pequeńas cavidades, densidad de cavidades media. } \\
\text { Inclusiones muy pequeñas: cuarzo, litoclastos negros, muscovita. }\end{array}$ \\
\hline TACRBDAALERS 4 & $\begin{array}{l}\text { Cuerpo y base de molde circular. La base de apoyo no es completamente plana, presentando un } \\
\text { pequeño reborde en sus laterales. Porción de molde de forma semicircular. Cocción oxidante irregular. } \\
\text { Medidas: espesor máximo } 21 \mathrm{~mm} \text {, mínimo } 15 \mathrm{~mm} \text {, sobre sector semicircular } 9 \mathrm{~mm} \text {. Ancho máximo } \\
5 \mathrm{~mm} \text {. Diámetro estimado del fragmento: } 7 \mathrm{~cm} \text {. Profundidad del molde: } 5 \mathrm{~mm} \text {. Presenta una pátina } \\
\text { o adherencia blanca en la superficie interna, sobre la forma semicircular. Pasta de aspecto compacto, } \\
\text { textura compacta. Pequeńas y escasas cavidades. Inclusiones: cuarzos, muscovita. }\end{array}$ \\
\hline TACRBDAALERS 5 & $\begin{array}{l}\text { Fragmento de molde de forma indeterminada. Presenta ambas superficies alisadas de manera irregular, } \\
\text { una de las cuales tiene una coloración más oscura que la otra. Cocción oxidante irregular. Medidas: } \\
\text { Largo } 69 \mathrm{~mm} \text {, ancho } 35 \mathrm{~mm} \text {. Espesor } 18 \mathrm{~mm} \text {. Pasta de aspecto compacto, textura porosa, fractura de } \\
\text { tipo terrosa. Pasta con pequeñas cavidades. Inclusiones: cuarzos, litoclastos negros, muscovita, tamaño } \\
\text { muy pequeńo. }\end{array}$ \\
\hline TACRBDAALERS 7 & $\begin{array}{l}\text { Fragmento de molde correspondiente a la base. Ambas superficies alisadas aunque una de ellas es más } \\
\text { uniforme. Cocción oxidante irregular. Medidas: Largo } 44 \mathrm{~mm} \text {, ancho } 48 \mathrm{~mm} \text {. Espesor } 22 \mathrm{~mm} \text {. Pasta de } \\
\text { aspecto compacto, textura compacta, fractura irregular, cavidades escasas y alargadas. Inclusiones de } \\
\text { cuarzos, plagioclasas, litoclastos grises. }\end{array}$ \\
\hline TACRBDAALERS 8 & $\begin{array}{l}\text { Fragmento de cuerpo de molde, en una superficie presenta una pared y en la otra (la de apoyo) un } \\
\text { orificio circular. Superficie de molde plana y pared de forma oblicua. Superficies alisadas de manera } \\
\text { uniforme pero tienen un estado de conservación regular. Cocción oxidante irregular. Medidas: altura } \\
\text { máxima } 38 \mathrm{~mm} \text {, ancho } 49 \mathrm{~mm} \text {, ancho de cuerpo } 23 \mathrm{~mm} \text {. Pasta de aspecto compacto, textura compacta, } \\
\text { pequeńos poros redondeados. Inclusiones: muscovita, cuarzo y escasos litoclastos negros de tamańo } \\
\text { pequeńo. }\end{array}$ \\
\hline TACRBDAALERS 10 & $\begin{array}{l}\text { Fragmento de molde, de base redondeada. Presenta las superficies alisadas aunque están notablemente } \\
\text { alteradas. Cocción oxidante irregular. Medidas: } 41 \mathrm{mmx} 45 \mathrm{~mm} \text { de largo y ancho. Espesor máximo } \\
23 \mathrm{~mm} \text {, mínimo } 20 \mathrm{~mm} \text {. Sobre la superficie interna pátina blanca y, sobre ésta, residuos de metal. Pasta } \\
\text { de aspecto compacto, textura porosa, fractura de tipo terrosa. Pequeńas cavidades. }\end{array}$ \\
\hline
\end{tabular}




\begin{tabular}{|c|c|}
\hline TACRBDAALERS 14 & $\begin{array}{l}\text { Fragmento de molde, superficie de apoyo alisada y de forma convexa. Cuerpo de molde presenta una } \\
\text { forma semicircular o redondeada. Superficies alisadas de forma irregular. Cocción oxidante irregular. } \\
\text { Medidas: ancho máximo } 49 \mathrm{~mm} \text {, ancho mínimo } 46 \mathrm{~mm} \text {, espesor máximo } 20 \mathrm{~mm} \text {, espesor mínimo } \\
9 \mathrm{~mm} \text {. } \\
\text { En un sector del molde, se hallan restos de residuo de color verde y pátina blanca. Pasta de textura } \\
\text { compacta, fractura uniforme. Poros pequeños, densidad media. Inclusiones: cuarzos y muscovita muy } \\
\text { pequeña. }\end{array}$ \\
\hline TACRBDAALERS 17 & $\begin{array}{l}\text { Fragmento de cuerpo y base, de molde de } 2 \text { piezas. Sobre la superficie del cuerpo se encuentra una } \\
\text { pared que divide } 2 \text { moldes. Tratamiento de superficie alisado irregular. Cocción no oxidante. Notables } \\
\text { manchas por termo-alteración. Medidas: ancho total } 65 \mathrm{~mm} \text {, largo } 52 \mathrm{~mm} \text {, altura tomada entre base y } \\
\text { protuberancia que separa formas de objetos } 33 \mathrm{~mm} \text {, altura entre base y concavidad } 20 \mathrm{~mm} \text {. Ancho de la } \\
\text { base } 41 \mathrm{~mm} \text {. Ancho de molde completo } 19 \mathrm{~mm} \text {, profundidad } 14 \mathrm{~mm} \text { (el otro está incompleto). Ancho de } \\
\text { la protuberancia que divide sectores de moldes } 11 \mathrm{~mm} \text {. En superficie con molde, presencia de residuos } \\
\text { de metal entrampado sobre las paredes. Pasta compacta, no se distinguen antiplásticos. Muy pequeńos. }\end{array}$ \\
\hline TACRBDAARS 103 & $\begin{array}{l}\text { Fragmento de molde, forma indeterminada. Base y cuerpo. Superficies alisadas de manera irregular. } \\
\text { Cocción no oxidante. } \\
\text { Medidas: espesor mínimo pared } 17 \mathrm{~mm} \text {, máximo } 26 \mathrm{~mm} \text {. } \\
\text { Pasta: fondo de pasta criptofilitosa y microgranosa, con inclusiones de cuarzo, feldespatos, } \\
\text { plagioclasas, cuarzos de origen metamórfico y sedimentario, muscovitas. }\end{array}$ \\
\hline TACRBDAARS 104 & $\begin{array}{l}\text { Fragmento de molde. Base y cuerpo. Tratamiento de superficie alisado irregular. Cocción no oxidante. } \\
\text { Medidas: Espesor mínimo pared } 13 \mathrm{~mm} \text {, máximo } 28 \mathrm{~mm} \text {. Fondo de pasta criptofilitosa y microgranosa } \\
\text { con inclusiones de cuarzo, feldespatos, plagioclasas, cuarzos de origen metamórfico y sedimentario, } \\
\text { muscovitas, pómez. }\end{array}$ \\
\hline
\end{tabular}

3) Intermediarios: dentro de este grupo encontramos cucharas y tapones. Son utilizadas para la transferencia del metal líquido desde un crisol hacia un molde. Las cucharas se diferencian de los crisoles en que poseen un orificio en su base, para verter el metal fundido. El tapón era empleado para abrir o cerrar esa perforación.

En Tacuil se han hallado evidencias del uso de ambos tipos de intermediarios: un fragmento de cuchara (TACRBDAALERS 1) y un tapón (TACRBDAALERS 18) (Tabla 4). El primero presenta borde, cuerpo y base de la pieza. En el centro de esta última se encuentra un orificio. Sobre la superficie externa se presenta un canal que corre en sentido horizontal alrededor de la circunferencia de la pieza y paralelo al borde. Según González (2010) y Gluzman (2011) este canal habría servido para colocar un agarre o enmangue que permitiera sostener la pieza.
El fragmento de tapón es de forma ligeramente curva $y$ en uno de sus extremos presenta forma aplanada.

También encontramos un refractario de forma subrectangular que presenta huellas de líneas incisas paralelas entre sí y evidencias de termoalteración [TACRBDAAR15C2N16 (3)], cuyas características nos remiten a la forma que Gluzman (2011) denominara como fragmentos con sobre-aplique con surcos, posiblemente parte de sistemas de cierre y unión de las cajas de moldes complejos. El mismo presenta una pasta porosa y fina y mide $45 \mathrm{~mm}$ de largo por $31 \mathrm{~mm}$ de ancho y $14 \mathrm{~mm}$ de espesor. Además, se registraron fragmentos que no pudieron asignarse a ninguno de estos grupos, por lo que fueron considerados como indeterminados. 
Tabla 4. Grupo de fragmentos de intermediarios de los recintos bajos de Tacuil, DAA.

Características tecno-morfológicas, métricas, tipo de cocción y pasta.

\begin{tabular}{|c|l|}
\hline $\begin{array}{l}\text { Fragmentos } \\
\text { de intermediarios }\end{array}$ & Características morfológicas y tecnológicas. Medidas. Tipos de pasta \\
\hline \multirow{7}{*}{ TACRBDAALERS 1 } & $\begin{array}{l}\text { Fragmento de borde y cuerpo de cuchara, de base plana, con orificio en el centro. Borde evertido, } \\
\text { labio convexo irregular. Sobre la superficie externa, a } 33 \mathrm{~mm} \text { del borde, canal que corre en sentido } \\
\text { horizontal alrededor de la circunferencia de la pieza y paralelo al borde. Superficies alisadas. Cocción } \\
\text { oxidante irregular. Medidas: Diámetro de la boca: } 13 \mathrm{~cm} \text {. Diámetro del orificio de la base: } 14 \mathrm{~mm} . \\
\text { Altura máxima de la pieza } 11,8 \mathrm{~cm} \text {. Espesor de paredes: del borde } 13 \mathrm{~mm} \text {; en pared del cuerpo } 18 \mathrm{~mm}, \\
\text { sobre pared de la base } 22 \mathrm{~cm} . \\
\text { Sobre la superficie interna se puede observar presencia de un residuo o pátina blanca y manchas negras } \\
\text { quizás producto de exposición al fuego o como residuo de uso. Pasta de aspecto compacto desgranable. } \\
\text { Textura porosa, fractura quebradiza. Cavidades pequeńas. Inclusiones de cuarzos, litoclastos negros, } \\
\text { muscovita, feldespatos o plagioclasas. Tamańo de las inclusiones: medianas y pequeñas. }\end{array}$ \\
\hline TACRBDAALERS 18 & $\begin{array}{l}\text { Tapón de forma sub-cilíndrica en sector del cuerpo y, hacia uno de los vértices, de forma aplanada. } \\
\text { Superficies alisadas. Las superficies se hallan notablemente alteradas por efecto del fuego } \\
\text { (fragmentación en capas, diversa coloración). Medidas: Largo } 53 \text { mm, ancho 28mm en sector aplanado } \\
\text { y 25mm en el cuerpo. Espesor: } 23 \text { mm en el cuerpo y } 17 \mathrm{~mm} \text { en sector aplanado. Presencia de residuo } \\
\text { blanco cubriendo gran parte de la superficie de la pieza, también una coloración rojiza, manchas } \\
\text { negras y evidencias de vitrificación. } \\
\text { Pasta de compacta, fina. Fractura quebradiza por alteración térmica. }\end{array}$ \\
\hline
\end{tabular}

\section{Metodología de estudio}

El abordaje de las evidencias de producción metalúrgica recuperadas en los recintos bajos de Tacuil fue realizado entendiendo la tecnología metalúrgica y cerámica como una red de operaciones técnicas que incluyen componentes como materia prima, energía, objetos, gestos, conocimientos (Lemonnier, 1992). Los mismos se desarrollan dentro de un marco social e histórico determinado (Roux, 2011) e involucran manifestaciones sociales-simbólicas y conocimientos propios de cada grupo (Lemonnier, 1992).

La metodología de análisis implicó la caracterización morfotecnológica y métrica de los materiales. Se consideraron atributos de manufactura de las piezas y estudios de pastas complementando con mediciones cualicuantitativas de elementos químicos sobre muestras de metal entrampado y de sustancia blanquecina presente en los fragmentos refractarios.

La caracterización de pastas fue realizada mediante lupa binocular (modelo M51000-40X) y lupa digital (BW-40X) y se realizaron cortes delgados sobre dos fragmentos de moldes. La observación petrográfica constó de una primera instancia con descripción de tipo cualitativa de cada corte, buscando determinar elementos constitutivos de las pastas y características generales (tamaño de inclusiones y poros, grado de esfericidad). En una etapa posterior, de índole cuantitativa, se llevó a cabo el conteo de puntos de cada muestra tomando un mínimo de 250 por lámina delgada. Los cortes delgados fueron realizados en el Laboratorio de Petrotomía y analizados en el laboratorio de Microscopía de la Escuela de Geología de la Facultad de Ciencias Naturales, ambos pertenecientes a la Universidad Nacional de Salta. Se utilizó microscopio de polarización Olympus BX51, completando el registro con microfotografías de los cortes.

De las muestras recuperadas se seleccionaron los dos fragmentos de metal y seis refractarios, de los cuales tres son moldes (TACRBDAARS 2, TACRBDAARS 10 y TACRBDAARS 17), dos fragmentos de crisoles (TACRBDAARS 6 y TACRBDAARS 15) y un tapón de cuchara (TACRBDAARS 18). En estos últimos, se observó macroscópicamente la presencia de restos de metal entrampado, sectores vitrificados y pátina blanquecina en alguna de sus superficies. Para conocer la composición de los metales y residuos depositados en los refractarios, los mismos fueron caracterizados mediante mi- 
croscopía electrónica de barrido y análisis composicionales cualicuantitativos puntuales a través de espectrometría de dispersión de energía de rayos $\mathrm{X}$ (EDS). Se empleó el equipo E-SEM Quanta 200 con EDAX Apollo 40 del Laboratorio de Investigaciones de Metalurgia Física de la Facultad de Ingeniería de la Universidad Nacional de La Plata. Los resultados presentados (Tablas 5 a 8) no incluyen los elementos que conforman la cerámica refractaria.

\section{Fragmentos de metal}

En cuanto a los dos fragmentos metálicos, el primero, recuperado en cercanías de la tumba $\mathrm{C}$, es de un tamaño de 3 x $3 \mathrm{~mm}$ y $1 \mathrm{~mm}$ de espesor (TACRBDAATCRSm 1). El segundo es también de tamaño pequeño 3,5 × $3 \mathrm{~mm}$ y 1 a $2 \mathrm{~mm}$ de espesor y fue hallado en el sector que denominamos Ladera este, espacio donde se registró la mayor cantidad de materiales refractarios (TACRBDAALERSm 1). Los mismos fueron analizados sin efectuar limpieza $y$, posteriormente, buscando generar una superficie limpia con una lima, aunque el estado de oxidación avanzado de los mismos no permitió conseguir un sector metálico sin óxido en ninguno de los casos (Tabla 5). No obstante, los resultados de los análisis cualicuantitativos presentados no incluyen los elementos de la pátina de oxidación. Más allá de la presencia de hierro, azufre y plomo en algunas de las mediciones, mayormente en bajísimos porcentajes, los datos obtenidos nos indican que ambos fragmentos están compuestos por cobre.

\section{Tecnología para la producción de cerámica refractaria: las pastas y sus componentes}

La caracterización submacroscópica de las evidencias de cerámica metalúrgica permitió diferenciar entre pastas gruesas, medianas y finas (Figura 5). Entre las primeras encontramos un fragmento de molde (TACRBDAARS 103). Las pastas medianas corresponden a moldes y cuchara, mientras que las finas son de moldes. Las pastas gruesas presentan abundante cantidad de antiplástico (sobre 30\%), con mayor cantidad de inclusiones que son de tamaño mediano y grueso. Este grupo ha sido caracterizado a partir del análisis microscópico de un corte que presenta una estructura de fondo criptofilitosa y microgranosa, con inclusiones de cuarzo, feldespatos, plagioclasas, cuarzos de origen metamórfico y sedimentario, y muscovitas (TACRBDAARS 103).

Tabla 5. Resultados de análisis de composición, medición por SEM, de fragmentos de metales de los recintos bajos de Tacuil, DAA.

\begin{tabular}{|c|c|c|c|c|}
\hline Metales & $\mathrm{Cu}$ & $\mathrm{Fe}$ & $S$ & $\mathrm{~Pb}$ \\
\hline TACRBDAATCRSm 1 & 96,91 & 1,77 & 0 & 1,24 \\
\hline TACRBDAATCRSm 1 & 96,86 & 1,75 & 0 & 1,36 \\
\hline TACRBDAATCRSm 1 & 96,33 & 3,44 & 0,24 & 0 \\
\hline TACRBDAATCRSm 1 & 100 & 0 & 0 & 0 \\
\hline TACRBDAATCRSm 1 & 100 & 0 & 0 & 0 \\
\hline Promedio & 98,024 & 1,392 & 0,048 & 0,52 \\
\hline TACRBDAALERSm 1 & 95,57 & 2,31 & 0 & 2,1 \\
\hline TACRBDAALERSm 1 & 93,9 & 2,89 & 0 & 3,19 \\
\hline TACRBDAALERSm 1 & 100 & 0 & 0 & 0 \\
\hline TACRBDAALERSm 1 & 98,38 & 1,64 & 0 & 0 \\
\hline TACRBDAALERSm 1 & 98,75 & 0 & 1,23 & 0 \\
\hline Promedio & 97,32 & 1,368 & 0,246 & 1,058 \\
\hline
\end{tabular}




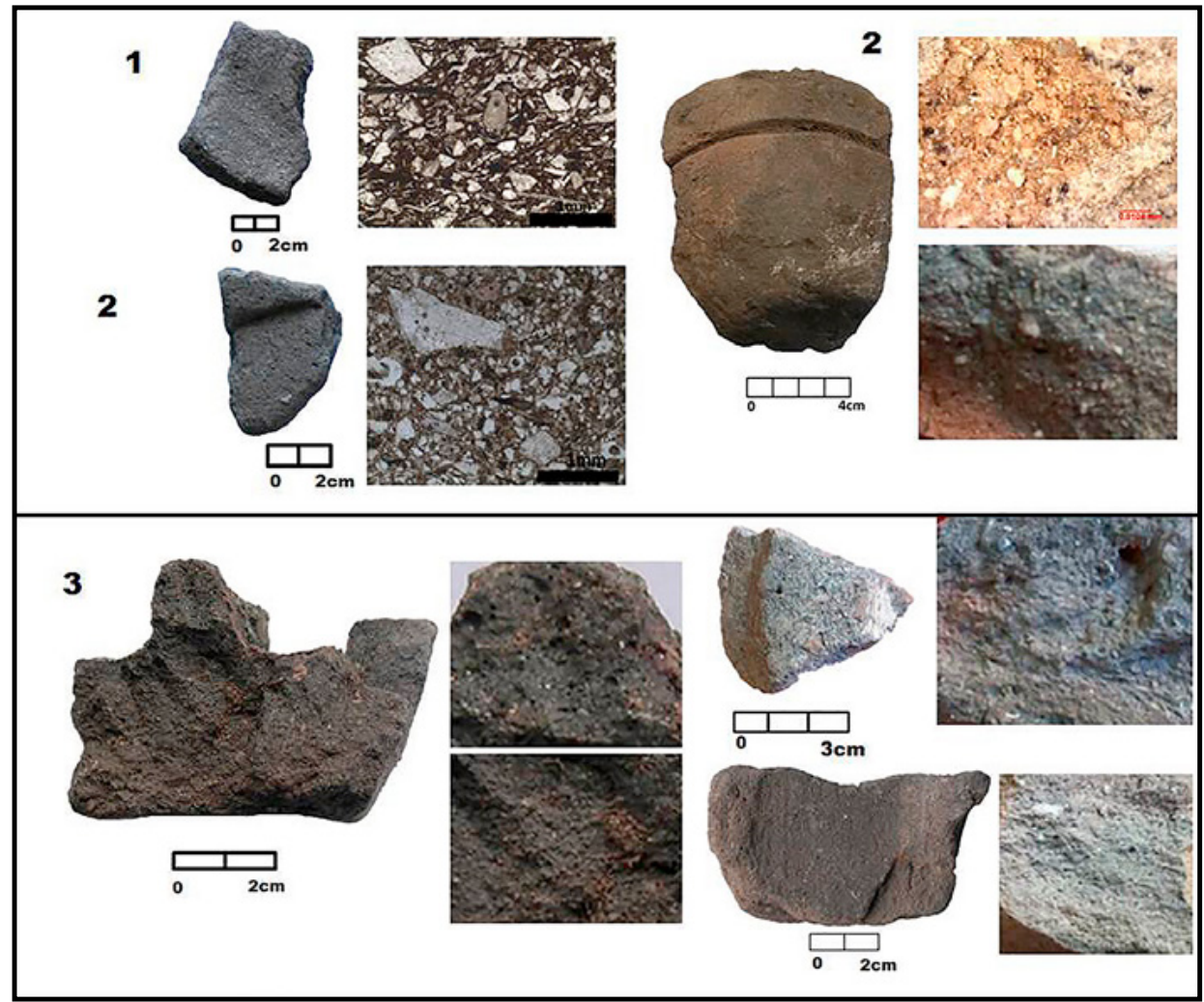

Figura 5. Pastas observadas en refractarios de Tacuil.

1: pastas gruesas. 2: pastas medianas. 3: pastas finas. (Imágenes de las autoras).

Las pastas medianas contienen entre un 20 y $30 \%$ de antiplástico, de tamaño fino (principalmente) y mediano. Este grupo ha sido definido mediante lupa binocular y, en un caso, por medio de análisis microscópico. Comprende fragmentos de crisoles, moldes (TACRBDAARS 104) y de una cuchara (TACRBDAARS 1). En lupa se han caracterizado pastas desgranables, con presencia de minerales de cuarzo principalmente, muscovitas y minerales opacos. Bajo microscopio, se observó un corte de molde de estructura de fondo criptofilitosa y microgranosa, con inclusiones de cuarzo, feldespatos, plagioclasas, cuarzos de origen metamórfico y sedimentario, muscovitas y pómez en pequeño porcentaje $(0,7 \%)$ (TACRBDAARS 104).

Las pastas finas presentan escaso antiplástico, de tamaño fino principalmente, abundantes poros y texturas compactas. Las mismas fueron caracterizadas a partir de lupa binocular. Encontramos aquí fragmentos de moldes (p.e., TACRBDAARS 17).

\section{La cerámica refractaria y sus usos para la producción metalúrgica}

Los análisis mediante microscopio electrónico de barrido y EDS realizados sobre los seis refractarios seleccionados dieron cuenta de la presencia de cobre en los diferentes grupos morfológicos (crisoles, moldes e intermediarios).

Para el caso de los dos fragmentos de crisoles, se observó la presencia en las superficies internas de sectores vitrificados de tonalidad oscura y pátina blanquecina por debajo de estos y en sus alrededores (Tabla 6). En el caso del crisol TACRBDAALERS 6 , los análisis de EDS en cuatro puntos ( 1 a 4 ) del área vitrificada arrojaron un promedio de $61,4 \% \mathrm{w}$ de cobre, con hierro $(3 \%$ w). Se detectó la presencia de calcio y fósforo, y también azufre en porcentajes muy bajos (máximo 0,48\%w). A efectos comparativos, se caracterizó un sector externo a esta capa oscura, donde no se detectaron ni cobre ni azufre. 
Los análisis realizados en el área vitrificada del crisol TACRBDAALERS 15 (1 a 3) indican una mayor proporción de cobre $(94,1 \%$ promedio) y mínima de calcio y fósforo. En esta última muestra también se observó un sector vitrificado en la superficie externa, que fue analizado (T1 a T3). Los resultados arrojan composiciones variables de cobre y mayor cantidad de hierro en comparación con el vitrificado interno. En un solo punto se detectó azufre. La presencia de calcio y fósforo aquí también es muy baja.

Los datos obtenidos del estudio de ambos crisoles sugieren que fueron recubiertos por una sustancia compuesta principalmente por calcio y fósforo $y$ empleados para la fundición de cobre.

En el caso de los moldes, analizamos tres muestras que presentaban pátina blanca e inclusiones metálicas. En el molde doble (TACRBDAALERS 2) se observa la presencia de restos de pátina blanca en una de las concavidades, donde efectuamos tres análisis (1 a 3), que arrojaron altos porcentajes de calcio y fósforo.
En el molde TACRBDAALERS 10, se analizó un sector que presentaba una inclusión metálica verdosa (1 a 3) y el sedimento blanquecino sobre el que se apoya la misma (4). Se pudo observar así que la inclusión metálica consiste en una aleación de cobre con estaño (41,59\%w promedio). Presenta también hierro en baja proporción. En uno de los puntos se detectó arsénico $(3,9 \%$ w), además de calcio y fósforo en bajos porcentajes, posiblemente como parte de la pátina blanca que se encuentra por debajo. En el punto tomado sobre el sedimento blanquecino se detectó cobre en menor proporción (16,6\%w), y principalmente calcio $(50,9 \% \mathrm{w})$ y fósforo $(9,7 \% \mathrm{w})$, como también alto contenido de hierro $(22,8 \% \mathrm{w})$.

En el molde TACRBDAALERS 17 (con concavidades para dos posibles cinceles/barras) se realizaron análisis sobre las inclusiones metálicas verdosas que se encuentran entrampadas en el borde/tabique entre ambos moldes (1, 2 y mapeo). Estas están constituidas principalmente por cobre $(87,5 \% \mathrm{w})$ con cantidades mínimas de hierro y plomo y de elementos de la pátina blanquecina (calcio y fósforo). En un mapeo realizado en una de estas inclusiones metálicas se

Tabla 6. Resultados de análisis de composición, medición por SEM, de fragmentos de crisoles de los recintos bajos de Tacuil, DAA.

\begin{tabular}{|c|c|c|c|c|c|}
\hline Crisoles muestra & $\mathrm{Cu}$ & $\mathrm{Fe}$ & $\mathbf{C a}$ & $S$ & $\mathbf{P}$ \\
\hline TACRBDAALERS 6-1 & 64,72 & 2,47 & 23,15 & 0,48 & 9,18 \\
\hline TACRBDAALERS 6-2 & 62,00 & 4,73 & 24,58 & 0,19 & 8,51 \\
\hline TACRBDAALERS 6-3 & 81,30 & 1,93 & 12,47 & 0,40 & 3,88 \\
\hline TACRBDAALERS 6-4 & 37,47 & 3,11 & 41,69 & 0,47 & 17,27 \\
\hline Promedio & 61,37 & 3,06 & 25,47 & 0,39 & 9,71 \\
\hline TACRBDAALERS 15-1 & 95,26 & 1,34 & 2,12 & 0,24 & 1,01 \\
\hline TACRBDAALERS 15-2 & 91,71 & 2,94 & 4,27 & 0,08 & 1,00 \\
\hline TACRBDAALERS 15-3 & 95,24 & 1,19 & 2,82 & 0,10 & 0,64 \\
\hline Promedio & 94,07 & 1,82 & 3,07 & 0,14 & 0,88 \\
\hline TACRBDAALERS 15-T1 & 59,56 & 27,45 & 13,00 & 0 & 0 \\
\hline TACRBDAALERS 15-T2 & 92,05 & 4,97 & 1,73 & 0,54 & 0,68 \\
\hline TACRBDAALERS 15-T3 & 59,15 & 36,20 & 4,68 & 0 & 0 \\
\hline Promedio & 70,25 & 22,87 & 6,47 & 0,18 & 0,23 \\
\hline
\end{tabular}


detectó azufre en baja proporción. También se analizaron sectores rojizos en la base de la concavidad (E1 a E5) y alrededor de dichas inclusiones (E7 a E9). Estos presentan altos porcentajes de estaño $(50,6 \% \mathrm{w}$ en promedio en la base de la concavidad) con mucha menor proporción de cobre (casi ausente en el caso de las mediciones E1 a E5) (Tabla 7).

En síntesis, los resultados obtenidos nos permiten afirmar que los moldes fueron empleados para la confección de objetos de cobre y/o bronce estańífero y que también se utilizó una pátina blanquecina de calcio y fósforo como recubrimiento del refractario. Debe señalarse, sin embargo, que resulta destacable la distribución no homogénea de cobre y estaño como residuos en dos de los moldes. Nos preguntamos si se debe a las características heterogéneas de la aleación empleada o si el molde fue utilizado en al menos dos oportunidades para la confección de objetos de bronce en una y de cobre sin alear en la

Tabla 7. Resultados de análisis de composición, medición por SEM, de fragmentos de moldes de los recintos bajos de Tacuil, DAA.

\begin{tabular}{|c|c|c|c|c|c|c|c|c|}
\hline Moldes & $\mathrm{Cu}$ & $\mathbf{F e}$ & $\mathrm{Ca}$ & $\mathbf{P b}$ & Sn & $S$ & $\mathbf{P}$ & As \\
\hline TACRBDAALERS 2-1 & 0 & 2,12 & 68,57 & 0 & 0 & 0 & 29,31 & 0 \\
\hline TACRBDAALERS 2-2 & 0 & 27,74 & 56,73 & 0 & 0 & 0 & 15,60 & 0 \\
\hline TACRBDAALERS 2-3 & 0 & 3,14 & 68,77 & 0 & 0 & 0 & 28,11 & 0 \\
\hline Promedio pátina blanca & $\mathbf{0}$ & 11 & 64,69 & $\mathbf{0}$ & $\mathbf{0}$ & $\mathbf{0}$ & 24,34 & $\mathbf{0}$ \\
\hline TACRBDAALERS 10-1 & 58,61 & 3,16 & 5,27 & 0 & 27,30 & 0,86 & 0,90 & 3,89 \\
\hline TACRBDAALERS 10-2 & 26,12 & 4,36 & 7,24 & 0 & 61,10 & 0,25 & 0,93 & 0 \\
\hline TACRBDAALERS 10-3 & 55,01 & 2,67 & 4,55 & 0 & 36,36 & 0,58 & 0,83 & 0 \\
\hline Promedio inclusión verde & 46,58 & 3,40 & 5,69 & $\mathbf{0 , 0 0}$ & 41,59 & 0,56 & 0,89 & 1,30 \\
\hline TACRBDAALERS 10-4 & 16,59 & 22,81 & 50,87 & 0 & 0 & 0 & 9,72 & 0 \\
\hline Total pátina blanquecina & 16,59 & 22,81 & 50,87 & $\mathbf{0}$ & $\mathbf{0}$ & $\mathbf{0}$ & 9,72 & $\mathbf{0}$ \\
\hline TACRBDAALERS 17-1 & 90,33 & 5,86 & 2,56 & 1,25 & 0 & 0 & 0 & 0 \\
\hline TACRBDAALERS 17-2 & 92,50 & 1,91 & 3,88 & 1,71 & 0 & 0 & 0 & 0 \\
\hline TACRBDAALERS 17-Mapeo & 79,69 & 4,00 & 13,18 & 0 & 0 & 0,42 & 2,67 & 0 \\
\hline Promedio inclusión verde & 87,51 & 3,92 & 6,54 & 0,99 & $\mathbf{0}$ & 0,14 & 0,89 & $\mathbf{0}$ \\
\hline TACRBDAALERS 17-E1 & 1,52 & 6,93 & 36,41 & 0 & 52,22 & 0,25 & 2,62 & 0 \\
\hline TACRBDAALERS 17-E2 & 1,45 & 11,01 & 37,07 & 0 & 46,81 & 0 & 3,67 & 0 \\
\hline TACRBDAALERS 17-E3 & 0 & 0 & 3,35 & 0 & 93,11 & 0 & 1,14 & 0 \\
\hline TACRBDAALERS 17-E4 & 1,99 & 12,02 & 40,09 & 0 & 33,65 & 0 & 12,19 & 0 \\
\hline TACRBDAALERS 17-E5 & 4,14 & 10,64 & 42,82 & 0 & 27,37 & 0 & 15,09 & 0 \\
\hline Promedio sector rojizo en molde & 1,82 & 8,12 & 31,95 & $\mathbf{0}$ & 50,63 & 0,05 & 6,94 & $\mathbf{0}$ \\
\hline TACRBDAALERS 17-E7 & 60,02 & 4,24 & 24,95 & 0 & 8,44 & 0,30 & 2,04 & 0 \\
\hline TACRBDAALERS 17-E8 & 55,31 & 4,64 & 37,90 & 0 & 0 & 0,49 & 1,67 & 0 \\
\hline TACRBDAALERS 17-E9 & 38,81 & 3,61 & 12,22 & 0 & 43,63 & 0,25 & 1,45 & 0 \\
\hline Promedio sector rojizo borde & 51,38 & 4,16 & 25,02 & $\mathbf{0}$ & 17,36 & 0,35 & 1,72 & $\mathbf{0}$ \\
\hline
\end{tabular}


Tabla 8. Resultados de análisis de composición, medición por SEM, de fragmento de intermediario de los recintos bajos de Tacuil, DAA.

\begin{tabular}{|l|c|c|c|c|c|c|}
\hline Intermediario & $\mathbf{C u}$ & Fe & Ca & Sn & S & P \\
\hline TACRBDAALERS 18-E1 & 36,54 & 2,00 & 37,72 & 9,51 & 0,50 & 13,72 \\
\hline TACRBDAALERS 18-E2 & 15,23 & 2,39 & 58,64 & 0 & 1,40 & 22,35 \\
\hline TACRBDAALERS 18-E3 & 48,69 & 2,11 & 35,16 & 0 & 0,35 & 13,67 \\
\hline TACRBDAALERS 18-E4 & 53,05 & 1,77 & 33,20 & 0 & 0,57 & 11,41 \\
\hline TACRBDAALERS 18-E5 & 48,14 & 9,41 & 34,56 & 0 & & 0 \\
\hline
\end{tabular}

otra, explicando así las adherencias de diversa composición. ${ }^{6}$

En relación a la última muestra, el análisis del fragmento de tapón (TACRBDAALERS 18) se realizó en un sector oscuro que cubre parte del mismo, en el lado que debió haberse insertado en la cuchara (E1 y E4 en zona lisa del tapón, E2 y E3 en sector rugoso). Los resultados muestran la presencia de cobre con una mínima proporción de hierro y azufre junto a altos porcentajes de fósforo y calcio. En uno de los puntos se detectó estaño $(9,5 \% \mathrm{w})$. Un sector externo a esta zona oscura (E5), también presenta cobre, calcio y fósforo, aunque con un mayor porcentaje de hierro $(9,4 \%$ w) (Tabla 8). En este caso también podemos explicar la presencia de estaño y cobre solo en una de las mediciones por la reutilización de esta cuchara para vaciar en moldes cobre solo o bronce en distintos eventos. Otra posibilidad para explicar que las adherencias metálicas tengan tan diferentes composiciones es que la cuchara haya sido empleada en la mezcla de cobre con estańo para elaborar la aleación, distribuyéndose diferencialmente estos elementos como residuos en el tapón durante este proceso.

\section{Discusión de resultados: aproximación a la cadena operativa de la producción metalúrgica en Tacuil}

Desde lo morfológico pudimos reconocer tres tipos de cerámicas refractarias asociadas a la producción metalúrgica: crisoles, moldes e intermediarios.

6 Zagorodny et al. (2015) han informado de evidencias de reutilización de refractarios en sucesivos eventos de fundición en el sitio Campo del Carrizal, Belén, Catamarca.
Además, encontramos fragmentos que no pudieron asignarse a estos grupos, por lo que fueron considerados bajo el rótulo de indeterminados. Con respecto a los crisoles, en todos los casos tenemos fragmentos pequeños que no presentan canal perimetral interno. Entre los moldes observamos variedad en las formas, aunque no todos pudieron ser asignados a una morfología particular. Este conjunto comprende un molde doble (el molde de hachas en $\mathrm{T}$ ); moldes con esquina redondeada, moldes con curvatura pronunciada $y$, posiblemente, un fragmento con sobre-aplique con surcos (sensu Gluzman, 2011). Entre los intermediarios, hallamos un fragmento de una cuchara y un fragmento de tapón.

Para el caso de los moldes, se observan huellas de alisado regular y, en algunos casos, de presiones digitales para su confección. Mientras que en dos crisoles y la cuchara, se distingue la superposición de rodetes o rollos de arcilla para su manufactura.

Las caracterizaciones y comparaciones de pastas de los distintos grupos (a nivel macroscópico y petrográfico) permitieron observar diferencias tecnológicas entre crisoles y moldes. Esto se asemeja a lo observado por Plaza y Martinón Torres (2014) y Zagorodny et al. (2015), quienes señalan diferencias petrográficas entre crisoles y moldes para sitios del Período Tardío del área central chilena, en el primer caso, y del valle de Belén, Catamarca, para el segundo. Para moldes del sitio Rincón Chico 15, se describen pastas de cerámicas refractarias de grano grueso con inclusiones que oscilan entre el 44 y $74 \%$ y una abundante porosidad (entre el 12 y $35 \%)$. En este caso, el principal componente observado es el del vidrio volcánico (Gluzman, 2015). 
En líneas generales podemos señalar que las pastas de los crisoles de Tacuil cuentan con un aspecto compacto, una textura porosa, su fractura es irregular y presentan inclusiones de tamańo pequeño en mediana densidad. De acuerdo con estudios de especialistas, sabemos que la porosidad mejora la transferencia de calor y aumenta la resistencia del cuerpo de la pieza al interrumpir la propagación de rupturas en su pasta o matriz (Gluzman, 2015). En este sentido, por ejemplo, para el sitio inca de Ingenio del Arenal Médanos, Catamarca, Scattolin y Williams (1992) encuentran cuencos para depositar el material para fundir (crisoles) cuya pasta es porosa, con inclusiones de granito, feldespatos y muscovitas y con fractura friable. Se observa una gran cantidad de antiplásticos de tamaño pequeño e improntas de pajuelas o restos vegetales, lo cual podría indicar adición de material orgánico, que sería una estrategia para aumentar la porosidad de los crisoles (Tylecote, 1982, p. 235, citado en Scattolin y Williams, 1992, p. 73).

Para los moldes de Tacuil hemos podido observar dos tipos de pastas, una de aspecto y textura compacta, de fractura regular y con escasos antiplásticos muy pequeńos. La segunda, con aspecto compacto y textura terrosa o desgranable y abundancia de antiplásticos medianos y grandes. Entre los antiplásticos pudimos observar en dos muestras de moldes la presencia de inclusiones de cuarzo, feldespatos, plagioclasas, cuarzos de origen metamórfico y sedimentario, muscovitas y pómez (en un caso), material usado como temperante o antiplástico que puede ser obtenido a nivel local. Este tipo de litología aporta mayor resistencia a la pieza, lo cual tuvo que ser necesario para la manipulación dentro de la producción metalúrgica (Gluzman, 2015). El mayor espesor de paredes que presenta la cerámica refractaria con respecto al resto de vasijas cerámicas ha sido también considerado un aspecto tecnológico que otorgaba una alta resistencia física al shock térmico (Gluzman, 2011).

Hasta el momento, y debido a que nos encontramos en una etapa inicial en las investigaciones sobre metalurgia en Tacuil, no estamos en condiciones de señalar a qué puede obedecer la diferencia de dos tipos de pastas en los moldes. La continuidad en los trabajos permitirá remarcar o desestimar dicha diferencia y dar nuevas interpretaciones sobre ello.
Como mencionamos, hemos destacado la presencia de una pátina blanquecina en las superficies de crisoles, moldes e intermediarios. Los análisis de caracterización de dicha sustancia mostraron que contiene altos porcentajes de calcio y fósforo. Aunque se hacen necesarios otros análisis (por ejemplo, difracción de rayos $\mathrm{X}$ ), los elementos presentes en estas pátinas nos sugieren que se trata posiblemente de hidroxiapatita $\mathrm{Ca}_{5}\left(\mathrm{PO}_{4}\right)_{3}(\mathrm{OH})$, detectada en otros moldes y crisoles prehispánicos analizados para el NOA (p.e., González, 1992; Raffino et al., 1996; Gluzman, 2011; Zagorodny et al., 2015). El empleo de esta pátina o sustancia blanquecina, generada a partir de la mezcla de cenizas de huesos con una solución, habría facilitado el desmolde de la pieza y minimizado irregularidades en las superficies de los objetos de metal elaborados. La aplicación de esta sustancia ha sido considerada como un conocimiento compartido, por ejemplo, con especialistas metalúrgicos del valle de Yocavil durante el Período Tardío y posteriormente en momentos Inca (González, 2004).

En cuanto al uso de estos refractarios, podemos decir que los mismos fueron empleados en determinadas etapas de la actividad metalúrgica, probablemente de fundición de minerales de cobre o cobre metálico (por medio del uso de crisoles) y de elaboración de objetos metálicos a partir del vaciado en moldes (posiblemente a partir de la cuchara con tapón) de cobre solo o bronce estañífero, con impurezas de hierro, plomo y azufre en algunos casos. La presencia de estos elementos puede deberse a la composición original de la mena utilizada para la obtención del metal (p.e., el hierro contenido en la calcopirita) o al agregado de algún fundente ferroso, si la roca de caja de la mena fundida estuviera compuesta por sílice (González, 2004; Zagorodny et al., 2015). Los bajos porcentajes de plomo en todos los casos nos hace pensar más bien en una impureza producto de la mena de origen de los minerales que de un agregado intencional. En cuanto a la presencia en bajas proporciones de azufre en algunas de las muestras, podría tratarse del producto de fundición de una mena de cobre rica en este elemento (sulfuro de cobre). Queda abierta la pregunta sobre si la ausencia de estos elementos en algunas de las muestras y su presencia en otras se debe o no al empleo de minerales de diferentes menas. 
En cuanto a los fragmentos metálicos, sus dimensiones no nos permiten identificar si corresponden a porciones de artefactos terminados (y en ese caso a qué tipo de piezas), si se trata de láminas de metal recortadas de objetos y descartadas o si forman parte de reservorios de metal empleados para ser combinados luego en aleaciones (con estaño, p.e.) o fundidas/martilladas para la confección de artefactos.

Recientes trabajos realizados sobre piezas de metal de la Colección Zavaleta del Museo Etnográfico (FFyL, UBA) y Museo Arqueológico Dr. Eduardo Casanova (Instituto Interdisciplinario de Tilcara) procedentes de tumbas excavadas en Tacuil permitieron reconocer instrumentos cortantes como cinceles, hachas, tumis y una campana (Castellanos y Becerra, 2019). A partir del cruce de información, observamos que algunos de los fragmentos de moldes recuperados en los recintos bajos de Tacuil dan cuenta de la producción local de piezas de similar morfología y función que las registradas en colecciones. Podemos considerar, entonces, que se trataría de una producción para consumo local. Lamentablemente, no contamos con datos sobre la procedencia exacta de las piezas de la colección Zavaleta, ni los contextos, que nos permitieran hipotetizar sobre la circulación y asociación de dichos objetos.

Hasta el momento, como mencionamos, no se han identificado estructuras de fundición en Tacuil. Sabemos de la existencia de evidencias de hornos en La Encrucijada en el valle Calchaquí norte, cerca de la Poma (Rodríguez Orrego, 1986), en Rincón Chico en el valle de Yocavil, Catamarca (González, 2010) y en Quillay en el valle de Hualfín, Catamarca (Raffino et al., 1996; Spina, Giovannetti y Ferraris, 2017). Pero también del hallazgo de simples estructuras de rocas en forma de respaldos, en banqueta y semicírculo como las mencionadas por Salazar et al. (2013) para el norte chileno. Experimentaciones han mostrado cómo en el caso de los óxidos de cobre el proceso de fundición puede ser muy sencillo y requerir únicamente un crisol o un pozo excavado, poco profundo, donde se coloque el mineral y el combustible (Killick, 2014).

Las evidencias de producción metalúrgica en Tacuil nos hace preguntarnos sobre la posible proveniencia de los minerales procesados. Los depósitos de cobre cercanos a este asentamiento se encuentran hacia el oeste, en la actual Puna salteña, en el Salar de Diablillos e Inca Viejo (oro y cobre) y en la manifestación Don Alberto, a $20 \mathrm{~km}$ al sudeste de la mina Incahuasi, mineralización de cobre con malaquita, azurita y crisocola (Hongn y Seggiaro, 2001). Este se encuentra cerca del sitio Abra de Minas, donde Gabriel López y equipo vienen realizando interesantes aportes sobre la ocupación estatal y la explotación de minerales de cobre (López y Coloca, 2015; López, Coloca, Araya, Orsi y Seguí, 2015). Hacia el este, en la localidad de El Monte, Seclantás, se encuentran minerales de malaquita; en Brealito hallamos afloramientos de cobre y en el Área Vallecito, en la sierra de Aguas Calientes, a $18 \mathrm{~km}$ al sur de la finca Pucará, al sudoeste de Angastaco en el Calchaquí medio, es posible encontrar minerales de cobre con malaquita, azurita, y menor proporción de cuprita y crisocola. En este sector se encuentran las minas San Francisco I y II, que cuentan con $60 \mathrm{~m}$ de galerías y varias labores menores que, a la fecha, se hallan inactivas (Hongn y Seggiaro, 2001, p. 65). Se ha mencionado, además, la existencia de un socavón en un cerro cerca de Jasimaná y de una probable explotación minera antigua en las cercanías del cerro Blanco (Alfredo Castillo, com. pers., 6 de noviembre, 2015). Precisamente este último cerro es un paso natural a la actual mina de Tincalayu y a los depósitos mineros de la puna de Salta (Figura 6).

No debemos olvidar tampoco que en el Macizo del Acay se encuentran depósitos de malaquita y azurita y sulfuros de cobre (Hongn y Seggiaro, 2001). Allí se emplazan diversos asentamientos que evidencian explotaciones mineras por lo menos desde momentos históricos (Mignone, 2014), y que fueran referidos en documentación temprana. Por ejemplo, en el relato de Torreblanca de 1696 (Torreblanca [1696] 2007) se comenta que uno de los padres que estaban en la misión de San Carlos había "ido al ingenio del Acay a buscar campanas para las iglesias de las misiones del valle" (folio 134, p. 103). Asimismo, el religioso seńala que en este asentamiento, al momento en que se inició el tercer levantamiento indígena, se estaba explotando una mina de cobre a donde él solía ir a confesar a los indios que allí residían (folio 13, p. 27). Aunque no sabemos si efectivamente esta mina estaba siendo explotada durante el siglo XVII. Es necesario entonces cruzar la información de los 


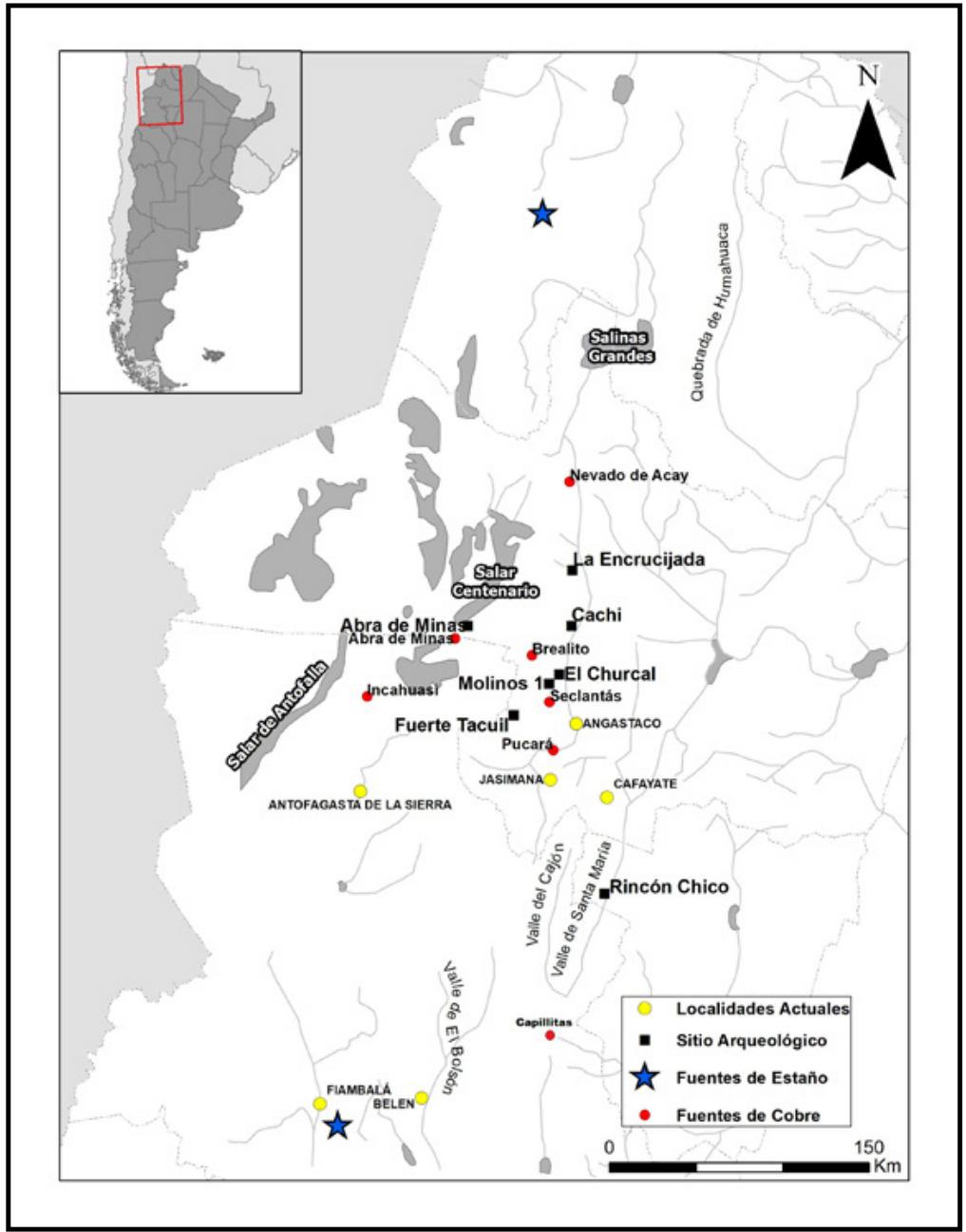

Figura 6. Localización de los sitios arqueológicos y depósitos minerales mencionados en el texto. En rojo: depósitos de minerales de cobre y cobre. En azul: depósitos de estaño cercanos al valle Calchaquí. (Imagen tomada y modificada de Villegas (2014, p. 20)).

documentos eclesiásticos con otros tipos de fuentes. Es de destacar, además, que durante la Conquista española, el ideal de hallar grandes riquezas como las metalíferas constituyó un importante elemento para fomentar la ocupación y explotación de la mano de obra, como bien lo señalara Gluzman (2007). Recordemos que Pedro Bohorques ${ }^{7}$ utilizó como un recurso

7 El español Pedro Bohorques es un personaje importante en la historia del Tucumán, a donde llega a mediados del siglo XVI y es amparado por los paciocas. Desde aquí se autotitula como descendiente de la élite cusqueña logrando convocar a diferentes poblaciones del valle Calchaquí y unirlas en las luchas de resistencia indígena frente al dominio colonial. Obtiene también, por par- para su reconocimiento ante la Corona, dar a conocer la localización de minas que eran explotadas por las poblaciones locales en los valles (Lorandi y Boixadós, 1987-1988). También hay que tener en cuenta que en Capillitas, provincia de Catamarca, se encuentran minas de cobre que fueron explotadas desde el Período Temprano y Tardío-Inca, tal como lo evidencian los restos arqueológicos (Scattolin y Williams, 1992).

Con respecto al estaño, los yacimientos más cercanos se encuentran en la puna norte de Jujuy (Angiorama

te del gobernador Alonso de Mercado y Villacorta, el título de Teniente de Gobernador y Capitán General (Lorandi, 1997). 
y Becerra, 2010) y en las Sierras de Belén y Fiambalá en Catamarca (Angelelli et al., 1970, citado en Sprovieri, 2013, p. 90). Para el caso de la Puna jujeña, se ha sugerido la posibilidad de que algunos minerales extraídos allí hayan sido transportados como parte de redes de circulación manejadas por caravaneros (Angiorama, 2006, 2011). Sprovieri menciona el hallazgo de obsidiana de la fuente de Laguna Blanca/Zapaleri en El Churcal, sobre el valle troncal del Calchaquí, señalando la vinculación entre este valle y la puna de Jujuy a partir de la circulación de este recurso, pero también sugiriendo la posibilidad de que el estaño utilizado para la producción metalúrgica en el valle Calchaquí provenga de esta región (Sprovieri, 2014, p. 355). Por otra parte, Tacuil se emplaza también en un sector de conexión natural a zonas con recursos de maderas (los algarrobales de fondo de valle o maderas duras del piedemonte oriental); además de contar con depósitos de arcillas y materiales que pueden ser utilizados como antiplásticos para la confección de los refractarios como los analizados en esta oportunidad.

\section{Consideraciones finales}

El estudio de las evidencias analizadas provenientes del sitio de Tacuil nos permite sugerir una producción metalúrgica local cuyos espacios utilizados no estaban desvinculados de la vida cotidiana. Se ha postulado que durante el Tardío o PDR en el NOA la tecnología metalúrgica estuvo asociada a actividades especializadas, planteando que los artesanos metalurgistas tenían conocimientos propios de la tecnología cerámica que les permitía producir las piezas con las que luego confeccionarían los objetos metálicos (González, 2004).

Asimismo, hemos podido distinguir ciertas características de la metalurgia local (como posibles tipos de objetos metálicos manufacturados a partir de los moldes hallados y el uso de la pátina blanca en los distintos refractarios empleados), que permiten considerar una base de producción similar a la desarrollada en el NOA durante el Período Tardío o PDR (ca. 900 DC a 1400 DC), coherente con los fechados absolutos que tenemos hasta el momento para la ocupación de los recintos bajos de Tacuil y también para el pukara homónimo (Williams, 2010). Esta cronología coincide con la que podemos establecer de manera indirecta a partir de la alfarería, la cual se asocia a estilos como el Santa María, Belén pulido, Negro pulido del Tardío, además de cerámica de manufactura tosca con superficies alisadas y peinadas. Por otra parte, la presencia de cerámica de estilo Belén Inca en los recintos bajos de Tacuil y de maquetas y bloques con cochas y líneas serpenteantes asignadas en otras regiones a momentos Inca (ver Cruz, 2015) sugieren que este asentamiento siguió siendo ocupado durante la llegada de los incas al NOA y al valle Calchaquí, en particular (ca. 1400 DC a 1536). Hasta el momento, en Tacuil no se han identificado indicadores materiales diagnósticos que denoten cambios en el paisaje a partir de la expansión incaica en la zona. Esto nos lleva a pensar, aunque de manera hipotética, que la producción metalúrgica a partir del siglo XIV continuó sin modificaciones aparentes con respecto a la tradición local previa. Es preciso también tener en cuenta que las fuentes escritas sugieren que este asentamiento estuvo habitado hasta mediados del siglo XVII, momento en el cual se da fin a los levantamientos indígenas que se extendieron a lo largo de los valles (Lorandi y Boixadós, 1987-1988). Investigaciones futuras nos permitirán brindar una cronología más ajustada de la ocupación de dichos recintos bajos y, por tanto, de las actividades metalúrgicas allí desarrolladas, como también del destino y circulación de las piezas producidas a partir de la anexión de estos territorios a la esfera estatal incaica.

Si bien nos encontramos en una etapa inicial de los trabajos sobre metalurgia en este sitio, remarcamos el potencial de la zona en cuanto a los recursos necesarios para la producción metalúrgica (minerales, combustibles, arcillas). Es preciso también ahondar en los contextos de hallazgo y asociación entre las diferentes muestras analizadas, para poder entender mejor la cadena de operaciones en la que las mismas estuvieron insertas, que aquí solo vislumbramos, como también de los posibles minerales empleados y sus fuentes de aprovisionamiento. Pero además es fundamental continuar los trabajos en campo, remarcando la importancia de hacer indagaciones extramuros, para así aportar al conocimiento sobre las prácticas metalúrgicas y cerámicas durante momentos tan cambiantes y conflictivos como los de los siglos XV a XVII. 


\section{Agradecimientos}

Los trabajos se realizaron en el marco de los proyectos PICT Nº 0042 (2013-2017), financiado por la Agencia Nacional de Promoción Científica y Tecnológica, y PIP Nº 0379 (2015-2017), financiado por el Consejo Nacional de Investigaciones Científicas y Técnicas, ambos dirigidos por V. Williams. Agradecemos a las comunidades y representantes de la base territorial de Tacuil y a la familia Dávalos, por permitirnos el ingreso al territorio. A Mirta Santoni, exdirectora del Museo de Antropología de Salta, y al personal de la institución. A los compañeros, compañeras y colegas de la Universidad Nacional de Salta y Universidad de Buenos Aires que participaron en los trabajos de campo. A los miembros del equipo de investigación por compartir información, en particular a Paula Villegas, Kevin Lane y Soledad Gheggi. A Luis Coll, por la modificación y actualización de los mapas y a Liliana Gassa por su ayuda con la interpretación de los datos obtenidos mediante SEM-EDS. A Carolina Orsini y Elisa Benozzi por permitir el uso de una imagen. A los evaluadores externos, que ayudaron a mejorar este trabajo. Todo lo aquí expuesto es de nuestra responsabilidad.

\section{Referencias citadas}

Ambrosetti, J. B. (1904). El bronce en la región Calchaquí. Anales del Museo Nacional de Buenos Aires, 11, 163-312.

Ambrosetti, J. B. (1907). Exploraciones Arqueológicas en la Ciudad prehistórica de La Paya (Valle Calchaquí, Provincia de Salta). Revista de la Universidad de Buenos Aires, VIII, 5-534.

Angiorama, C. (2003). Producción y circulación de objetos de metal en la Quebrada de Humahuaca en momentos prehispánicos tardios (900-1535 d.C.). Tesis doctoral inédita. Facultad de Ciencias Naturales e Instituto Miguel Lillo, Universidad Nacional de Tucumán, Tucumán, Argentina.

Angiorama, C. (2006). ¿Mineros quebradeños o altiplánicos? La circulación de metales y minerales en el extremo noroccidental de Argentina (1280-1535 A.D.). Intersecciones en Antropología, 7, 147-161.

Angiorama, C. (2011). La ocupación del espacio en el sur de Pozuelos (Jujuy, Argentina) durante tiempos prehispáni- cos y coloniales. Estudios Sociales del NOA, 11, 125-142.

Angiorama, C. y Becerra, M. F. (2010). Antiguas evidencias de minería y metalurgia en Pozuelos, Santo Domingo y Coyahuayma (puna de Jujuy, Argentina). Boletín del Museo Chileno de Arte Precolombino, 15(1), 81-104.

Baldini, L. (2003). Proyecto arqueología del Valle Calchaquí central (Salta, Argentina). Síntesis y perspectivas. En Cornell, P. y Stenborg, P. (Eds.). Local, Regional, Global: Prehistoria en los Valles Calchaquies. Anales Nueva Época, 6 (pp. 219-239). Göteborg, Suecia: Instituto Iberoamericano, Universidad de Göteborg.

Baldini, L. y Villamayor, V. (2007). Espacios productivos en la cuenca del río Molinos (Valle Calchaquí, Salta). Cuadernos FHyCS - UNJu, 32, 35-51.

Bertrand, A. (1885). Memoria sobre las cordilleras del Desierto de Atacama i rejiones limitrofes. Santiago, Chile: Imprenta Nacional.

Calderari, M. y Williams, V. (1991). Re-evaluación de los estilos cerámicos incaicos en el Noroeste Argentino. Comechingonia, 9, Número especial, 75-87.

Castellanos, M. C. (2017). Territorialidades, interacciones y materialidades en las quebradas altas del Calchaqui medio (Salta), durante los siglos XI a XVII. Tesis doctoral inédita. Facultad de Filosofía y Humanidades, Universidad Nacional de Córdoba, Córdoba, Argentina.

Castellanos, M. C. y Becerra, M. F. (2019). Los metales de la colección Zavaleta de Tacuil (Molinos, Salta) y su aporte al conocimiento de la secuencia de producción metalúrgica en las quebradas altas del Valle Calchaqui. Manuscrito.

Catálogo de la Colección Calchaqui de Arqueología y Antropología de Manuel B. Zavaleta (1906). Buenos Aires: Imprenta y librería Petenello Hnos.

Cigliano, E. M. y Raffino, R. (1975). Arqueología en la vertiente occidental del valle Calchaquí Medio. Relaciones de la Sociedad de Antropología Argentina, 9, 47-56.

Cruz, P. (2013). De wak'as, minas y jurisdicciones. Apuntes metodológicos en torno a la territorialidad en tiempos del Inka. En Presta, A. M. (Ed.). Aportes multidisciplinarios al estudio de los colectivos étnicos surandinos "Qaraqara-Charka. Reflexiones a tres años después” (pp. 293-330). La Paz: Plural Editores - Instituto Francés de Estudios Andinos. 
Cruz, P. (2015). Tatala Purita o el Influjo del Rayo. Arte Rupestre Anicónico en las Altas Tierras Surandinas (Potosí, Bolivia). Boletín del SIARB, 29, 51-70.

Giovannetti, M., Corrado, G., Cochero, G. Ferraris, E., Spina, J., Salama, C., Aljanati, L. y Valderrama, M. (2015). El Shincal de Quimivil, Quillay y Los Colorados. Una ventana para entender el mundo inka en la región central de Catamarca. En Rodríguez, R. (Coord.) y M. A. López (Ed. y Comp.). Arqueología y Paleontología de la Provincia de Catamarca (pp. 137-152). Buenos Aires: Fundación de Historia Natural Félix de Azara.

Gluzman, G. (2007). Minería y metalúrgica en la antigua gobernación del Tucumán (siglos XVI y XVII). Memoria Americana, 15, 157-184.

Gluzman, G. (2011). Producción metalúrgica y dinámica social en el Noroeste argentino (siglos XIII a XVII). Tesis doctoral inédita. Facultad de Filosofía y Letras, Universidad de Buenos Aires, Buenos Aires, Argentina.

Gluzman, G. (2015). Una tecnología olvidada. Las cerámicas metalúrgicas en el Noroeste argentino prehispánico. Boletin CIP, 29, 9-14.

González, A. R. (1979). Precolumbian metallurgy of Northwest Argentina. En Benson, E. P. (Ed.). Pre-Columbian Metallurgy of South America (pp. 133-202). Washington, DC: Dumbarton Oaks Research Library Collection.

González, A. R. (1992). Las placas metálicas de los Andes del Sur. Contribución al estudio de las religiones precolombinas. München: Materialien zur Allgemeinen und Vergleichenden Archäologie, Band 46.

González, L. (2002). Heredarás el bronce. Incas y metalurgia en el Sur del valle de Yocavil. Intersecciones en Antropología, 3, 55-68.

González, L. (2004). Bronces sin nombre. La metalurgia prehispánica en el Noroeste argentino. Buenos Aires: Fundación CEPPA.

González, L. (2010). Fuegos sagrados. El taller del sitio 15 de Rincón Chico (Catamarca, Argentina). Boletín del Museo Chileno de Arte Precolombino, 15(1), 47-62.

González, L. y Gluzman, G. (2007). Innovación y continuidad en la metalurgia incaica del Noroeste argentino. El caso del bronce. Mundo de Antes, 5, 187-210.
Holmberg, E. (1900). Viaje por la Gobernación de los Andes (Puna de Atacama). Buenos Aires: Ministerio de Agricultura de la República Argentina, Imprenta de la Nación.

Hongn, F. y Seggiaro, R. (2001). Hoja Geológica 2566-III Cachi. Provincias de Salta y Catamarca. República Argentina. Buenos Aires: Programa Nacional de Cartas Geológicas 1:250.000, Segemar.

Killick, D. (2014). From ores to metals. En Roberts, B. W. y Thornton, C. P. (Eds.). Archaeometallurgy in Global Perspective. Methods and Syntheses (pp. 11-45). New York, NY: Springer.

Lechtman, H. (1976). A Metallurgical Site Survey in the Peruvian Andes. Journal of Field Archaeology, 3(1), 1-42.

Lechtman, H. (1988). Traditions and styles in central Andean metalworking. En Madding, R. (Ed.). The beginning of the use of metals and alloys (pp. 344-378). Cambridge, UK: Mass press.

Lechtman, H. (1991). The production of copper-arsenic alloys in the Central Andes: highland ores and coastal smelters? Journal of Field Archaeology, 18(1), 43-76.

Lemonnier, P. (1992). Elements for an Anthropology of Technology. Anthropological Papers, Museum of Anthropology, 88, 1-24.

López, G. y Coloca, F. (2015). El sitio Abra de Minas: nuevos aportes para la caracterización de las ocupaciones Tardío/Incas en las tierras altas del noroeste argentino. Bulletin del 'Institut Français d'Études Andines, 44(1), 141-149.

López, G., Coloca, F., Araya, S., Orsi, J. P. y Seguí, S. (2015). El sitio cueva Inca Viejo, salar de Ratones, puna de Salta: evidencia arqueológica y procesos de interacción macro-regional. Revista de la Sociedad de Antropología Argentina, XL (1), 45-71.

Lorandi, A. M. (1997). De quimeras, rebeliones y utopias. La gesta del inca Pedro Bohorques. Perú: Fondo editorial PUCP.

Lorandi, A. M. y Boixadós, R. (1987-1988). Etnohistoria de los Valles Calchaquíes en los siglos XVI y XVII. Revista Runa, XVII-XVIII, 266-419.

Martinón Torres, M. y Rehren, T. (2014). Technical Ceramics. En Roberts, B. W. y Thornton, C. P. (Eds.). 
Archaeometallurgy in Global Perspective. Methods and Syntheses (pp. 107-131). New York, NY: Springer.

Mayer, E. (1986). Armas y herramientas de metal prehispánicas en Argentina y Chile. München: Kommision für Allgemaine und Vergleinchende Archaologie, Band 38.

Mignone, P. (2014). Fuentes para la localización y el estudio de las minas históricas del Nevado de Acay, departamento La Poma. Salta, Argentina. Memoria Americana, 22(1), 65-92.

Palamarczuk, V. (2011). Un estilo y su época: El caso de la cerámica Famabalasto Negro Grabado del Noroeste Argentino. Oxford, UK: Archaeopress, BAR International Series 2243.

Philippi, R. (1860) Viage al Desierto de Atacama, hecho de orden del gobierno de Chile en el verano 1853-1854. Sajonia: Librería Eduardo Anton.

Raffino, R. (1981). Los Inkas del Kollasuyu. La Plata, Argentina: Ramos Americana.

Raffino, R. (1983). Arqueología y Etnohistoria de la región Calchaquí. En Morresi, E. y Gutiérrez, R. (Dirs.). Presencia hispánica en la arqueología argentina. Vol. 2 (pp. 817-861). Entre Ríos: Museo Regional de Antropología e Instituto de Historia. Facultad de Humanidades. Universidad del Nordeste.

Raffino, R. (1984). Excavaciones en el Churcal (Valle Calchaquí, República Argentina). Revista del Museo de la Plata (Nueva serie), VII, 223-263.

Raffino, R., Gobbo, D., Iácona, A. y Moralejo, R. (2015). El Shinkal de Quimivil. Una capital Inka al sur del Kollasuyu. Buenos Aires: Fundación de Historia Natural Félix de Azara.

Raffino, R., Iturriza, R., Iácona, A., Capparelli, A., Gobbo, D., Montes, V. y Vázquez, R. (1996). Quillay: centro metalúrgico Inka en el Noroeste Argentino. Tawantinsuyu, 2, 59-69.

Rodríguez Orrego, L. (1986). La metalurgia precolombina de los Andes Meridionales. Una síntesis regional. En Metalurgia de América precolombina. $45^{\circ}$ Congreso Internacional de Americanistas (pp. 381-402). Bogotá: Banco de la República.
Roux, V. (2011). Anthropological interpretation of ceramic Assemblages: foundations and implementations of technological analysis Archaeological Ceramics: A review of current research. Inglaterra: BAR International Series 2193.

Salazar, D., Mille, B., Figueroa, V., Balestro, F., Perlès, C., Berenguer, J., Bourgarit, D., Corrales, P., Carroza, L. y Burens, A. (2013). Metalurgia indígena en el distrito Miño-Collahuasi, Norte de Chile (siglos X a XVII): tecnología y organización de la producción de cobre. En Bárcena, R. y Martín, S. (Eds.). Actas del XVIII Congreso Nacional de Arqueología Argentina (pp. 91-92). La Rioja, Argentina: Universidad Nacional de La Rioja - Instituto de Ciencias Humanas, Sociales y Ambientales (CONICET).

Scattolin, C. y Williams, V. (1992). Actividades minero metalúrgicas prehispánicas en el Noroeste argentino. Nuevas evidencias y su significación. Boletín del Instituto Francés de Estudios Andinos, 21(1), 59-87.

Serrano, A. (1976 [1958]). Manual de la cerámica indígena ( $3^{a}$ ed.). Córdoba, Argentina: Assandri.

Spina, J., Giovannetti, M. y Ferraris, E. (2017). Interrogantes de la metalurgia prehispánica Andina: nuevas propuestas desde los hornos de Quillay (Catamarca, Argentina). Chungara. Revista de Antropología Chilena, 49(3), 327-342.

Sprovieri, M. (2013). El mundo en movimiento: Circulación de bienes, recursos e ideas en el valle Calchaquí, Salta (Noroeste Argentino). Una visión desde La Paya. Oxford, UK: Archaeopress, British Archaeological Reports.

Sprovieri, M. (2014). La circulación interregional en el valle Calchaquí (Provincia de Salta, Noroeste argentino): una visión integral desde nuevas y viejas evidencias. Revista Española de Antropología Americana, 44(2), 337-366.

Tarragó, M. y González, L. (1998). La producción metalúrgica prehispánica en el asentamiento de Tilcara (Prov. Jujuy). En Cremonte, M. B. (Ed.). Los desarrollos locales $y$ sus territorios (pp. 179-198). San Salvador de Jujuy, Argentina: Universidad Nacional de Jujuy.

Torreblanca, H. (2007 [1696]). Relación Histórica del Calchaqui. Buenos Aires, Argentina: Archivo General de La Nación. Versión paleográfica de Teresa Piossek Prebisch. 
Vasvári, V. (2014). Evidencias de ocupación incaica en Payogastilla. Sector sur del valle Calchaqui. Tesis de grado inédita. Facultad de Humanidades, Universidad Nacional de Salta, Salta, Argentina.

Ventura, B. y Scambato, A. (2013). La metalurgia de los valles Orientales del Norte de Salta, Argentina. Boletín del Museo Chileno de Arte Precolombino, 18(1), 85-106.

Villegas, M. P. (2014). Del valle a la puna: articulación social y económica entre los poblados prehispánicos Tardios y los asentamientos inkas en la quebrada de Angastaco (valle Calchaqui medio, Salta). Tesis doctoral inédita. Facultad de Filosofía y Letras, Universidad de Buenos Aires, Buenos Aires, Argentina.

Williams, V. (2010). El uso del espacio a nivel estatal. En Albeck, M. E., Scattolin, C. y Korstanje, M. A. (Eds.). El Hábitat Prehispánico: Arqueología de la Arquitectura y de la construcción del Espacio Organizado (pp. 77-114). Jujuy, Argentina: Ediunju.

Williams, V. (2015). Formaciones sociales en el noroeste argentino. Variabilidad prehispánica en el surandino durante el Periodo de Desarrollos Regionales y el estado Inca. Haucaypata, Investigaciones arqueológicas en el Tahuantinsuyu, Año 4(9), 62-76.

Williams, V. (2019). Nuevos datos sobre las Quebradas altas del Calchaqui medio Salta, noroeste de Argentina (NOA). Reproducción local entre los siglos XI a XV. Manuscrito.
Williams, V. I. y Castellanos, M. C. (2018). Dinámicas regionales, poblaciones y territorios en el valle Calchaquí medio (Salta, Argentina) durante los siglos XII a mediados del XVII. En Muñoz, M. de los A. (Ed.). Interpretando huellas. Arqueología, Etnohistoria y Etnografía de los Andes y sus Tierras Bajas (pp. 247-266). Cochabamba, Bolivia: INIAM - UMSS. Editorial Khipus.

Williams, V. I. y Villegas, M. P. (2013). Colonización estatal en las cuencas de Angastaco-Molinos (Salta, Argentina). En Williams, V. y Cremonte, B. (Eds.). Al borde del imperio. Paisajes sociales, materialidad y memoria en áreas periféricas del Noroeste argentino (pp. 221-252). Buenos Aires: Publicaciones de la SAA.

Williams, V. I. y Villegas, M. P. (2017). Rutas y senderos como paisajes. Las quebradas altas del valle Calchaquí medio (Salta). Boletín Museo Chileno de Arte Precolombino, 22, 69-92.

Williams, V. I., Villegas, M. P., Gheggi M. S. y Chaparro, M. G (2005). Hospitalidad e intercambio en los valles mesotermales del Noroeste Argentino. Boletín de Arqueologia de la PUCP, 9, 335-373.

Zagorodny, N., Angiorama, C., Becerra, M. F. y Pérez Pieroni M. J. (2015). Evidencias de actividades metalúrgicas en el sitio Campo de Carrizal (Belén, Catamarca). Intersecciones en Antropología, 16, 439-450. 